\title{
Dynamic Fault Interaction during a Fluid-Injection-Induced Earthquake: The 2017 Mw 5.5 Pohang Event
}

- Kadek Hendrawan Palgunadi ${ }^{1} \quad$ : kadek.palgunadi@kaust.edu.sa

- Alice-Agnes Gabriel²

- Thomas Ulrich ${ }^{2}$

- José-Ángel Lopéz-Comino ${ }^{3 i}$

- Paul Martin Mai ${ }^{1}$
: gabriel@geophysik.uni-muenchen.de

: ulrich@geophysik.uni-muenchen.de

:lopezcomino@uni-potsdam.de

: martin.mai@kaust.edu.sa

1. Physical Science and Engineering, King Abdullah University of Science and Technology, Thuwal, Saudi Arabia

2. Department of Earth and Environmental Sciences, Geophysics, Ludwig-Maximilians-Universität München, Theresienstr. 41, 80333 Munich, Germany

3. Institute of Geosciences University of Potsdam, Potsdam-Golm, Germany. 


\title{
Palgunadi et al., 2020 BSSA Special Issue on Induced Seismicity PREPRINT
}

\begin{abstract}
:
The November $15^{\text {th }}, 2017 \mathrm{Mw}$ 5.5 Pohang earthquake (South Korea) has been linked to hydraulic stimulation and fluid injections, making it the largest induced seismic event associated with an Enhanced Geothermal System (EGS). To understand its source dynamics and fault interactions, we conduct the first 3D high-resolution spontaneous dynamic rupture simulations of an induced earthquake. We account for topography, off-fault plastic deformation under depth-dependent bulk cohesion, rapid velocity weakening friction and 1D subsurface structure. A guided fault reconstruction approach that clusters spatio-temporal aftershock locations (including their uncertainties) is used to identify a main and a secondary fault plane which intersect under a shallow angle of $15^{\circ}$. Based on simple Mohr-Coulomb failure analysis and 180 dynamic rupture experiments in which we vary local stress loading conditions, fluid pressure, and relative fault strength, we identify a preferred two-fault plane scenario that well reproduces observations. We find that the regional far-field tectonic stress regime promotes pure strike-slip faulting, while local stress conditions constrained by borehole logging generate the observed thrust faulting component. Our preferred model is characterized by overpressurized pore fluids, non-optimally oriented but dynamically weak faults and a close to critical local stress state. In our model, earthquake rupture "jumps" to the secondary fault by dynamic triggering, generating a measurable non-double couple component. Our simulations suggest that complex dynamic fault interaction may occur during fluid-injection induced earthquakes and that local stress perturbations dominate over regional stress conditions. Therefore, our findings have important implications for seismic hazard in active geo-reservoir.
\end{abstract}




\section{Palgunadi et al., 2020 BSSA Special Issue on Induced Seismicity PREPRINT}

\section{Introduction}

The Korean Peninsula is known to have a rather low-level of seismicity (compared to neighboring countries like China and Japan) because it lies on the continental margin of the east Eurasian plate. However, on November 15 ${ }^{\text {th }}, 2017$ (05:29:31 UTC), a magnitude Mw 5.5 earthquake occurred (hereinafter the Pohang earthquake), the second-largest recorded earthquake in South Korea following the $2016 M_{L} 5.8$ Gyeongju earthquake. The Pohang earthquake caused one fatality, injured 82 people, and generated more than $\$ 300$ millions in total economic loss (Ellsworth et al., 2019; Lee et al., 2019). The hypocenter was located approximately $10 \mathrm{~km}$ northeast of Pohang city, close to the Pohang Enhanced Geothermal System (EGS) site $\left(36.106^{\circ} \mathrm{N}\right.$, $129.373^{\circ} \mathrm{E}$ and depth $\sim 4.27 \mathrm{~km}$, Korean Government Commission, 2019). Its proximity to the EGS site and hypocentral depth similar to the open hole sections of the fluid-injection wells (Figure 1) quickly raised questions if this earthquake is associated with EGS activities (Grigoli et al., 2018; Kim et al., 2018).

The Pohang EGS project was designed to create an enhanced geothermal reservoir within a low permeability crystalline basement. The basement is overlain by cretaceous volcanic and sedimentary rocks, tertiary volcanic and sedimentary rocks, and quaternary sediments (Korean Government Commission, 2019; Ellsworth et al., 2019). During a period of four years (2012 to 2016), two geothermal wells (maximum depth $\sim 4.3 \mathrm{~km}$ ) were drilled for hydraulic stimulations. At the surface, both wells are separated by only $6 \mathrm{~m}$ distance, increasing to a separation of $599 \mathrm{~m}$ at a depth of $\sim 4.3 \mathrm{~km}$. For well PX-1, the drilling was stuck at a depth of $2419 \mathrm{~m}$, and hence sidetracked into west-northwest direction. Well PX-2 experienced large mud loss in the depth interval 3830 - $3840 \mathrm{~m}$, while cuttings contain significant fractions of friable round-shaped mud balls typical for fault gouge (Korean Government Commission, 2019; Ellsworth et al., 2019). In these 


\section{Palgunadi et al., 2020 BSSA Special Issue on Induced Seismicity PREPRINT}

geothermal wells, five hydraulic stimulations were conducted between 29 January 2016 and 18 September 2018. During this period, each hydraulic stimulation phase was associated with seismicity. The magnitudes during and after stimulations reached up to $M_{L} \approx 3$, while events were distributed within a restricted area close to the wells (Woo et al., 2019). The depth of the seismicity before the Pohang earthquake spans the depth range 3.8 to $4.4 \mathrm{~km}$, comparable with the open-hole section of the well at $\sim 4.3 \mathrm{~km}$ depth (Ellsworth et al., 2019).

Recent studies confirm that the Pohang earthquake was induced by hydraulic stimulation and extensive fluid injection at this EGS site (Korean Government Commission, 2019; Ellsworth et al., 2019; Woo et al., 2019; Kim et al., 2020). These activities are considered to have activated the previously unmapped fault which was found to intersect well PX-2 at a depth of $\sim 3.8 \mathrm{~km}$. Chang et al. (2020) point out that increased pore-pressure stressing due to multiple injection wells at the Pohang EGS site may have contributed to the mainshock generation. However, it has been argued that the size of fluid-injection induced earthquakes can be controlled by managing pressure, location, and rate of fluid injection (Hofmann et al., 2019). Data-driven empirical and numerical studies have shown that the induced earthquakes are confined by a function of injected volume (McGarr, 2014; Galis et al., 2017).

Grigoli et al. (2018) find a complex-source mechanism for the Pohang earthquake with a significant non-double couple (non-DC) component. They hypothesized that this earthquake involved failure on two different faults with slightly different focal mechanisms. In fact, in EGS reservoirs with extensive fluid injection and hydraulic stimulation, earthquakes with pronounced non-DC components may occur (Julian et al., 1998). Moreover, fluid injections may induce local deviation of the stress state from the regional stress regime (Schoenball et al., 2014; MartínezGarzón et al., 2013; Martínez-Garzón et al., 2014). Therefore, we examine how regional and local 


\section{Palgunadi et al., 2020 BSSA Special Issue on Induced Seismicity PREPRINT}

stress conditions acting on different fault models (single plane and two planes) determine the dynamic rupture process that leads to a source mechanism with non-DC components.

Dynamic rupture modeling aims to reproduce the physical processes that govern how earthquakes start, propagate, and stop for given stress and frictional conditions acting on fault surfaces. The earthquake dynamics are then a result of the model's initial conditions, such as geometry and frictional strength of the fault(s), the tectonic stress state, the regional lithological structure, and a frictional constitutive equation. Jin and Zoback (2018) model coseismic fully dynamic spontaneous fault rupture resulting from preseismic quasi-static loading exerted by fluid perturbations in a faulted porous medium in 2D. Duan (2016) model 2D dynamic rupture accounting for fluid effects of a propagating hydraulic fracture. Cappa and Ruitquist (2012) and Buijze et al. (2017) constrain the rupture onset in 2D dynamic rupture experiments by the stress state resulting from solving a coupled quasi-static poroelastic equation. Further 2D studies that model induced (not fully dynamic) earthquake rupture linked to the fluid diffusion equation including Galis et al. (2017); Kroll et al., (2017); Dieterich et al. (2015); Garagash and Germanovich (2012); Richards-Dinger and Dieterich (2012); Viesca and Rice (2012). Using modern numerical methods and advanced hardware, very realistic 3D simulations model explicitly the highly non-linear dynamic rupture process (e.g., Heinecke et al., 2014; Roten et al., 2014; Uphoff et al., 2017; Wollherr et al., 2019; Ulrich et al., 2019a, 2019b). The modeling results include spatial and temporal evolution of earthquake rupture, surface displacements, and ground shaking caused by the radiated seismic waves.

In this study, we investigate the dynamic rupture process under variable stress and faultgeometry assumptions for the Pohang earthquake, using the high-performance-computing (HPC) enabled software package SeisSol (see Data and Resources). Two alternative fault geometries are 


\section{Palgunadi et al., 2020 BSSA Special Issue on Induced Seismicity PREPRINT}

considered, a single-fault plane model (Model 1F) and a two-fault planes model (Model 2F). In our simulations, we consider a 1D velocity structure (Woo et al., 2019), off-fault plasticity (Wollherr et al., 2018), depth-dependent bulk cohesion, a rapid velocity weakening friction law, borehole estimates of stress, complex fault geometry, and high-resolution topography.

In the following, we first describe (Section Fault reconstruction) a new observationally guided fault reconstruction approach based on spatio-temporal clusters of microearthquakes and their spatial uncertainty. In Section Fault strength and loading stress, we analyze initial fault strength and loading stresses using static and dynamic rupture modeling. We then compare the dynamics and kinematics of the two preferred models, Model $1 \mathrm{~F}$ and $2 \mathrm{~F}$. The validation of Model 2F with regional waveforms, as well as a comparison of surface deformation between Model 1F and Model 2F are also presented in Section Results. Finally, we discuss the importance of considering local stresses loading, apparently weak and critically stressed faults, overpressurized fluids, and dynamic multiple fault interaction in EGS.

\section{Modeling Setup}

In the following, we describe our approach to produce a physically viable model constrained by observational data. Dynamic rupture propagation is governed by fault strength, fault geometry, subsurface material properties, topography, loading (“initial”) stresses, nucleation procedure, and empirical friction laws (Dunham et al., 2011a; Harris et al., 2011; Harris et al., 2018). Numerical experiments that vary the aforementioned parameters provide insights into fundamental earthquake physics and allow identifying self-consistent scenarios that explain the mechanical processes of the earthquake as well as observational data. 


\section{Palgunadi et al., 2020 BSSA Special Issue on Induced Seismicity PREPRINT}

\section{Fault reconstruction}

The detailed fault geometry has a strong effect on the dynamic rupture process (Ando and Kaneko, 2018; Kyriakopoulos et al., 2019; Ulrich et al., 2019a; Wollherr et al., 2019). Changes in strike, dip, and deviations from fault planarity can impact the rupture propagation and the corresponding physical processes. The Pohang earthquake occurred on one or several blind and unmapped fault(s). Because the unwrapped InSAR surface-displacement data show unclear fringes due to the small deformation around the epicenter (Choi et al., 2019; Song and Lee, 2019), we use the high-resolution earthquake catalog from Kim et al. (2018) to constrain the fault geometry based on a space-time (including their uncertainties in space) clustering approach. The earthquake catalog spans from 9 hours before to 3 hours after the mainshock and contains 217 events.

\section{Spatio-temporal clustering}

Clustering techniques allow deciphering complex fault structures by associating seismic events to groups (clusters), also discriminating events that are associated with the mainshock from uncorrelated earthquakes (background events); including background events may bias the fault reconstruction algorithm (see Section Fault plane fitting). We examine the seismic sequence to separate seismic clusters and background events using nearest-neighbor distances following Zaliapin and Ben-Zion (2013). The dependence of an event $i$ to a parent event $j$ is determined from the nearest-neighbor distance $\eta_{i j}$ :

$$
\eta_{i j}=d t_{i j} \times d r_{i j}{ }^{d}, d_{i j}>0 ; \eta_{i j}=\infty, d t_{i j}<0
$$




\section{Palgunadi et al., 2020 BSSA Special Issue on Induced Seismicity PREPRINT}

where $d t_{i j}=t_{j}-t_{i}$ is the time between event $i$ and $j, d r_{i j}=\left(r_{j}-r_{i}\right)$ is the interevent distance between events; $r_{i}=$ coordinate of event $i$ and $r_{j}=$ coordinate of event $j$, and $d$ is the fractal dimension of the earthquake hypocenter distribution (Hirata, 1989). We find that the inferred clusters are not very sensitive to parameter $d$; hence we set $d=1.6$ following previous studies (Zaliapin and Ben-Zion, 2013; Zhang and Shearer, 2016; Cheng and Chen, 2018). Based on this analysis, all earthquakes of the catalog classify as aftershocks and thus can be associated with the mainshock cluster and can be used for fault-plane fitting (see Figure 2a). This cluster is characterized by interevent distances less than $1 \mathrm{~km}$.

\section{Fault plane fitting}

We adopt the anisotropic clustering location uncertainty distribution (ACLUD) method, a fault-network reconstruction approach (Wang et al., 2013) that accounts for uncertainties in earthquake locations. This method is extended by considering regional tectonic constraints, focal mechanisms, and surface geological manifestation as prior information, leading to the following improvements in the original ACLUD algorithm:

1) Initialize $N_{0}$ number of faults following the predefined orientation of the $S_{H \max }$ extracted from the world stress map with random position and size.

2) For each cluster, if more than four similar focal mechanisms (strike, dip, rake) are available, we use this information to separate events that have distinct focal mechanisms into other clusters.

3) If surface geological manifestation (fault traces) exists (not the case for this study), the strike and dip of the generated fault segment(s) should follow the closest interpreted fault trace orientation. 


\section{Palgunadi et al., 2020 BSSA Special Issue on Induced Seismicity PREPRINT}

We refer to this modified ACLUD method as guided-ACLUD (g-ACLUD).

All explored solutions are subject to a statistical validation process that examines the likelihood of each proposed fault-network, given all available focal mechanisms. Statistical validation uses the Bayesian Information Criterion (BIC). Initially, the method uses a random number of fault planes. A single fault plane may be split into two separate planes if the BIC-value remains high. On the other hand, two close-enough fault planes with similar orientation (strike and dip) may be merged into a single fault plane. The process is repeated until the BIC-value reaches a predefined minimum or if the process exceeds the maximum specified number of iterations (Wang et al., 2013).

The ACLUD algorithm by Wang et al. (2013) uses event locations and associated uncertainties given by the earthquake catalog. We incorporate additional information to increase the robustness of the results and to decrease the explored parameter space. As a-priori information, we use the orientation of the maximum compressive regional stress given by the world stress map (Heidbach et al. 2018) and available focal mechanisms in the area which are associated with the earthquake catalog. Therefore, we use a maximum horizontal stress orientation of $74^{\circ}$ with an uncertainty of $25^{\circ}$ and consider the focal mechanism inferred by Grigoli et al. (2018). Since location errors are not specified in this earthquake catalog, we assume normally distributed uncertainty for all events (standard deviation of $100 \mathrm{~m}$ ). Note that Kim et al. (2018) obtained a median error of 42, 31, and $36 \mathrm{~m}$ in the EW, NS, and vertical directions, respectively, but no uncertainties for individual events.

Figure 2b, 2c, 2d show the g-ACLUD selected solution, characterized by the smallest BICvalue, which features two intersecting planar fault planes. The main plane strikes at $214^{\circ}$ and dips at $65^{\circ}$, while the secondary fault plane strikes at $199^{\circ}$ and dips $60^{\circ}$, respectively. The two fault 


\section{Palgunadi et al., 2020 BSSA Special Issue on Induced Seismicity PREPRINT}

planes are separated by a narrow angle of $15^{\circ}$. The secondary fault aligns with the subsidiary fault plane identified by Kim et al. (2018). The dimensions of the main and secondary fault planes are $4.3 \mathrm{~km} \times 2.8 \mathrm{~km}$ and $3.0 \mathrm{~km} \times 2.2 \mathrm{~km}$, respectively. As the goal of this study is to compare the rupture process for two different fault configurations, we define a geometry with one fault plane (Model 1F) or with two intersected fault planes (Model 2F; derived fault reconstruction analysis). The Model $1 \mathrm{~F}$ has a fault plane striking $214^{\circ}$ and dipping $43^{\circ}$, as suggested by Korean Government Commission (2019), Ellsworth et al. (2019), and Woo et al. (2019).

\section{Material properties}

We assume an elasto-plastic, isotropic medium based on the 1D velocity profile (Figure S1a; Woo et al. (2019)). The velocity profile honors geological structures observed from drilling cores and seismological observations from both active and passive sources, for instance, vertical seismic profiling (VSP) and well logging (Korean Government Commission, 2019; Woo et al., 2019). The density distribution (Figure S1a) is adopted from the report by Korean Government Commission (2019).

We use a computationally efficient implementation of a Drucker-Prager off-fault viscoplastic rheology (Wollherr et al., 2018). The off-fault failure criterion is based on the internal friction coefficient (bulk friction) and bulk cohesion. We assume a constant internal friction coefficient equal to the prescribed on-fault friction coefficient $\left(\mu_{\text {bulk-friction }}=0.6\right)$ for the entire model domain. However, bulk cohesion is set to be depth-dependent, accounting for geologic strata in the Pohang EGS site and the hardening of rocks with depth. Therefore, bulk cohesion ranges from $c=4 \mathrm{MPa}$ near the surface to $c=50 \mathrm{MPa}$ at a depth of $6 \mathrm{~km}$. A lower bulk cohesion (12.5\% of the surroundings) is applied in a $1.5 \times 0.3 \times 4 \mathrm{~km}^{3}$ volume around the fault intersection 


\section{Palgunadi et al., 2020 BSSA Special Issue on Induced Seismicity PREPRINT}

for the case of Model 2F to mimic pre-existing damage which enhances off-fault yielding and to prevent unrealistic high on-fault stresses at the fault intersection. Off-fault stresses are initialized consistently with the stresses acting on the fault, that is, the on-fault stress state is the resolution of the initial bulk stress tensor onto the surface of every fault element with respect to its individual orientation (with the exception of fault overstressing applied during rupture initiation, see Appendix Nucleation procedure). Finally, we set a constant, mesh-independent relaxation time following Wollherr et al., (2018) and chose $T_{V}=0.05 \mathrm{~s}$, consistently with choices made in previous studies (e.g. Ulrich et al., 2019a, 2019b).

\section{Fault strength and loading stresses}

To constrain the azimuth of the principal stress component and the overall stress regime, we extract information (e.g., $S_{H \max }$ orientation and fault strength) from laboratory and field observations. We then perform numerical experiments to identify the mechanically most viable fault stress and strength configuration supported by observations, that is, the optimal configuration which resolves sufficient shear traction to sustain dynamic rupture on both faults and which promotes fault slip oriented consistently with observations. We adopt a friction law with rapid velocity weakening (adapted from Dunham et al., 2011a; see Appendix, Friction parameters) which reproduces the rapid friction decrease observed in laboratory experiments at co-seismic slip rates (Di Toro et al., 2011).

We parametrize fault friction aiming for realistic levels of static and dynamic frictional resistance and stress drop. All frictional properties are detailed in Appendix (Friction parameters). We apply velocity weakening $(b-a=0.004)$ across the fault (see Figure S1b) and velocity strengthening $(b-a=-0.004)$ to the uppermost part of the fault, which allows for a 


\section{Palgunadi et al., 2020 BSSA Special Issue on Induced Seismicity PREPRINT}

smoother termination of the rupture there. The state evolution distance $(L)$, initial slip rate $\left(V_{\text {ini }}\right)$, reference slip velocity $\left(V_{0}\right)$, steady-state friction coefficient $\left(f_{0}\right)$, and weakened friction coefficient $\left(f \_w\right)$ are constant and depth-independent.

We follow the systematic approach of Ulrich et al. (2019a) to examine initial fault stress and relative apparent fault strength by combining data from observations (e.g., seismo-tectonic observations and fault fluid pressurization) and the Mohr-Coulomb theory of failure. This workflow reduces the non-uniqueness in dynamic rupture modeling parameter selection by assessing that the stress state is compatible with the fault geometry and the fault-slip orientation (rake angle) inferred from finite source or moment tensor inversion. Assuming a spatially uniform Andersonian stress regime (one principal stress axis is vertical), only four parameters are sufficient to fully describe the stress state and strength of the fault system: the azimuth of maximum compressive stress $\left(S_{\text {Hmax }}\right)$, the initial relative fault prestress ratio $\left(R_{0}\right)$, the stress shape ratio $(v)$, and the fluid pressure ratio $(\gamma)$, all detailed hereafter.

The Pohang EGS site is considered to be located within a strike-slip stress regime (Soh et al., 2018, and references therein). This translates into the maximum principal stress being horizontal $\left(\sigma_{1}=S_{H \max }\right.$, with principal stress components $\sigma_{1}>\sigma_{2}>\sigma_{3}>0$ ) under Andersonian stress. Previous studies examined the azimuth of maximum horizontal stress using different methods, such as borehole and seismological techniques, e.g., stress inversion of focal mechanisms (Kim et al., 2017; Lee et al., 2017; Lee, Hong, and Chang, 2017; Soh et al., 2018; Korean Government Commission, 2019; Ellsworth et al., 2019). Soh et al. (2018) inferred $S_{\text {Hmax }}$ from focal mechanisms of earthquakes that occurred between 1997 and 2016 and determined a regional $S_{\text {Hmax }}=74^{\circ}$. However, the earthquakes closest $(\sim 40 \mathrm{~km})$ to the Pohang EGS site used in their analysis are the 2016 Gyeongju event and its aftershocks. Based on borehole data, Kim et al. (2017) 


\section{Palgunadi et al., 2020 BSSA Special Issue on Induced Seismicity PREPRINT}

and Lee, Shinn, et al. (2017) determined that $S_{H \max }$ at shallow depths (700 m to $1000 \mathrm{~m}$ ) within a $10 \mathrm{~km}$ radius from the Pohang EGS is about $130^{\circ}$. In contrast, Ellsworth et al. (2019) and Korean Government Commission (2019) inferred a critically stressed thrust faulting regime. This stress state implies that the vertical stress is the least principal stress under Andersonian stress $\left(s_{v}=\sigma_{3}\right)$. They inferred an $S_{H \max }$ orientation of $77 \pm 23^{\circ}$ based on dipole sonic logging data. This orientation is similar to the value of $74^{\circ}$ given in the world stress map (Heidbach et al., 2018).

Using numerical simulations, we then assess how these loading-stress regimes for the inferred fault geometry determine nucleation and rupture of the Pohang earthquake. The stress shape ratio $v$ enables a contrast of different stress styles by balancing the principal stress amplitudes. It is defined as:

$$
v=\frac{\left(s_{2}-s_{3}\right)}{\left(s_{1}-s_{3}\right)}
$$

For strike-slip regimes $\left(\sigma_{2}=\right.$ vertical $), v<0.5$ characterizes transpression, $v \approx 0.5$ corresponds to pure strike-slip regime, and $v>0.5$ characterizes transtension (Ulrich et al., 2019a). Soh et al. $(2018)(v=0.12)$, Ellsworth et al., (2019) and Korean Government Commission (2019) $(v=0.1)$ suggests a stress regime accounting for transpression around the Pohang EGS site (note that they use different definition of $v$ ).

The initial relative prestress ratio $\left(R_{0}\right)$ describes the closeness to failure on a virtual, optimally oriented fault. $R_{0}=1$ indicates a critical stress level on all optimally oriented faults. We can characterize fault strength spatially by calculating the relative prestress ratio $(R)$ on every point of the fault. $R$ denotes the ratio of potential stress drop $\Delta \tau$ with respect to breakdown strength drop 


\section{Palgunadi et al., 2020 BSSA Special Issue on Induced Seismicity PREPRINT}

$\Delta \tau_{b}$ for given frictional cohesion $(c)$, static $\left(\mu_{s}\right)$ and dynamic $\left(\mu_{d}\right)$ friction coefficient (e.g., Aochi and Madariaga, 2003) expressed as:

$$
R=\frac{\Delta \tau}{\Delta \tau_{b}}=\frac{\tau_{0}-\mu_{d} \sigma_{n}}{c+\llbracket\left(\mu \rrbracket_{s}-\mu_{d}\right) \times \sigma_{n}}
$$

where $\tau_{0}$ and $\sigma_{n}$ are initial shear and normal traction on the fault plane, respectively. However, in this study, we neglect the contribution of frictional cohesion $(c=0)$, which is mostly important to incorporate close to the Earth's surface. We assume $\mu_{s}=f_{0}=0.6$ and $\mu_{d}=f_{w}=0.1$. The relative prestress ratio $R$ is related to the relative fault strength parameter $(S)$ defined as $S=\frac{1}{R}-$ 1. On-fault values of $R$ change at every point as we vary $R_{0}$, taking on values $R \leq R_{0}$ depending on the orientation of each fault point with respect to the optimal orientation.

The vertical principal stress is assumed to vary linearly with depth, consistent with the geological strata (depth-dependent density $(\rho)$ in Figure S1a). We assume the intermediate principal stress component, $\sigma_{2}$, to be vertical. The confining pressure of the overlying rock is reduced by the pore pressure $\left(P_{f}\right)$. We assume $P_{f}$ proportional to lithostatic stress as $P_{f}=\gamma \rho g z$, where $g$ is the gravitational acceleration $\left(9.8 \mathrm{~m} / \mathrm{s}^{2}\right), z$ denotes depth (in meters), and $\gamma$ is the fluid pressure ratio. A fluid pressure ratio of 0.37 indicates hydrostatic pore pressure, while $\gamma>0.37$ implies an overpressurized stress state.

We perform a range of static and dynamic numerical experiments described below to test the sensitivity of the resulting dynamic rupture models to the chosen stress parameterization in terms of $S_{\text {Hmax }}, R_{0}$ and $\gamma$. We keep the $4^{\text {th }}$ parameter, the stress shape ratio, fixed at $v=0.12$ (Soh et al., 2018). We do not adjust the stress states for the stress excess during nucleation (see 


\section{Palgunadi et al., 2020 BSSA Special Issue on Induced Seismicity}

PREPRINT

Appendix, Nucleation procedure). The overstressed nucleation and its parameters are constant for all 180 numerical experiments.

\section{Results}

We use the open-source software SeisSol (details in Appendix, Numerical method) to solve for spontaneous frictional failure on prescribed fault surfaces, Drucker-Prager off-fault plasticity and seismic wave propagation in complex media. We set the on-fault mesh size using estimates of cohesive zone width (details in Appendix, Mesh generation). We incorporate highresolution topography into our modeling. Figure 3 shows the computational mesh overlain by a snapshot of absolute velocity at $t=5 \mathrm{~s}$.

Next, we present 3D dynamic rupture simulations for scenarios that consider one fault plane (Model 1F) or two intersecting fault planes (Model 2F), incorporating depth-dependent regional loading stresses, off-fault plastic yielding, and high-resolution surface topography. In the preferred model (Model 2F), the secondary fault plane is dynamically triggered and can explain the observed non-double couple component of the moment tensor solution. Our model is compatible with regional waveforms (see Section Model 2F validation by regional waveform modeling) and agrees qualitatively with InSAR surface deformation analysis (see Section Model 1F and Model 2F surface deformations).

\section{Static and dynamic analysis of initial fault strength and stresses}

We first constrain the regional stress from a purely static analysis. Figure S2 shows a few cases we analyzed in detail (see also Table S1). The six examples shown use parameters $\gamma=0.5$ and $R_{0}=0.7$, and variable $S_{H \max }$ in the range $52^{\circ}-140^{\circ}$. According to the static analysis, 


\section{Palgunadi et al., 2020 BSSA Special Issue on Induced Seismicity PREPRINT}

assuming parameter selection in this study, $S_{H \max }<87^{\circ}$ is insufficient to generate a rake angle of shear traction compatible with the thrust-faulting component inferred by the focal mechanism and moment tensor solution. At $S_{\operatorname{Hax}} \geq 87^{\circ}$, a thrust-faulting component starts to emerge. Interestingly, only the secondary fault plane features a rake angle larger than $40^{\circ}$ for $S_{\text {Hmax }}=$ $77^{\circ}-140^{\circ}$. A rake angle of $\sim 80^{\circ}$, obtained with $S_{\operatorname{Hax}}=120^{\circ}$, can potentially produce the thrust-faulting component inferred by moment tensor solution. For this parameter selection, the secondary fault plane reaches a higher rake angle of approximately $110^{\circ}$.

We restrict the parameter space for $R_{0}$ and $\gamma$ based on our static analysis. We then explore 180 different dynamic rupture simulations by systematically combining five different values of $R_{0}$, with six different values for $\gamma$ and $S_{H \max }$, respectively. We vary $R_{0}$ in the range $0.7-0.9, \gamma$ within 0.37 - 0.9 and $S_{H \max }$ within $67-120^{\circ}$. Figure 4 summarizes the outcome of 180 numerical dynamic rupture experiments. We find that when assuming $R_{0}>0.8$ and under hydrostatic pore pressure $(\gamma=0.37), S_{\text {Hmax }}=120^{\circ}$ is the only value which promotes self-sustained ruptures in distinction to any other $S_{H \max }$ orientation.

Our modeling suggests that, at least in the framework of the simple parameterization adopted in this study, the thrust-faulting component generated when using $S_{H \max }=67^{\circ}-87^{\circ}$ is insufficient to explain seismological observations. Such $S_{\text {Hmax }}$ leads to pure strike-slip faulting as the only mechanical viable solution. Both dynamic and static analyses suggest that $S_{\text {Hmax }}=120^{\circ}$ is necessary to generate a thrust-faulting component close to the observations. Our analyses allow determining a preferred parameter selection, compatible with inferred ground deformation, observed regional waveforms, and the inferred focal mechanism: $R_{0}=0.8$ and $\gamma=0.5$. 


\section{Palgunadi et al., 2020 BSSA Special Issue on Induced Seismicity PREPRINT}

\section{Rupture dynamics of the preferred scenario Model 1F and Model 2F}

Figure 5a and Video S1 (in supplementary material) provide an overview of the simulated earthquake rupture of Model 2F: rupture propagates spontaneously across the main fault plane and dynamically triggers the secondary fault plane (rupture jumping).

The rupture nucleates smoothly due to the prescribed time-dependent overstress (see Appendix, Nucleation procedure) centered at the hypocenter location; it then spontaneously propagates bilaterally across the main fault plane. At a rupture time $t=0.60 \mathrm{~s}$, two successive slip rate fronts emerge, with lower peak slip rates than the main rupture front (two arrows on Figure $5 \mathrm{a}$, left). This rupture complexity is associated with the simultaneous rupture on both fault planes, leading to multiple reflected and trapped waves in-between the two fault planes, reactivating the main fault around the intersection. Rupture complexity decreases as rupture on the secondary fault plane terminates. After rupture time $t=0.80 \mathrm{~s}$, we observe solely pulse-like rupture propagation across the main fault.

The secondary fault plane is dynamically triggered at $t=0.4 \mathrm{~s}$ and its rupture terminates at $t=0.8 \mathrm{~s}$ simulation time, while the main-fault stops slipping at $t=1.5 \mathrm{~s}$ simulation time. The secondary fault plane ruptures only partially since its northern segment does not slip (Figure $5 b$ ).

High slip rates $(\sim 10 \mathrm{~m} / \mathrm{s}$, warm colors in Figure 5a, right) and multiple rupture fronts occur near the fault intersection at the secondary fault. Rupture heals close to the fault intersection region around $t=0.65 \mathrm{~s}$.

After $t=0.80 \mathrm{~s}$ rupture on the main fault dynamically clamps (e.g., Kyriakopoulos et al., 2019) and thus does not facilitate direct branching to the northern unbroken part of the secondary fault plane. We observe asymmetric peak slip rate distribution (see Figure S3), with higher values on the left of the main fault plane (Figure 5a, right panel) and lower peak slip rates where ruptures 


\section{Palgunadi et al., 2020 BSSA Special Issue on Induced Seismicity PREPRINT}

across directly adjacent fault planes interact, which is also associated with high off-fault plastic yielding (see section Off-fault deformation). The entire rupture is completed after $t \sim 1.5 \mathrm{~s}$ simulation time, breaking $4 \mathrm{~km}$ of fault length and generating a moment magnitude of $M_{w} 5.59$ (dominated by slip on the main fault plane). We find that rupture stops smoothly and spontaneously on the secondary fault plane and north-eastern part of the main fault plane, while being stopped abruptly by the southwestern fault end of the main fault plane.

In contrast to the Model $2 \mathrm{~F}$, the preferred single-plane fault model, Model $1 \mathrm{~F}$, produces symmetric bilateral slip rate and slip distributions.

\section{Rupture kinematics of the preferred Model 1F and Model 2F scenarios}

Due to the size of the event and limited available data, the kinematics of the Pohang earthquake are challenging to be quantified from source inversion. We here describe the model kinematics of the preferred Model $1 \mathrm{~F}$ and Model $2 \mathrm{~F}$ earthquake scenarios and then compare both with two observational studies (Song and Lee, 2019; Grigoli et al., 2018).

Song and Lee (2019) estimated the static slip distribution by InSAR (both descending and ascending-descending orbit) for a single fault plane with patch size $0.5 \mathrm{~km}$ by $0.5 \mathrm{~km}$. Higher slip predominantly occurs northeast of the hypocenter, with an average slip of $0.15 \mathrm{~m}$ (Song and Lee, 2019). Grigoli et al. (2018) applied an Empirical Green's Function (EGF) technique to study rupture duration and directivity, suggesting an apparent rupture duration of $\sim 1 \mathrm{~s}$ and $\sim 3 \mathrm{~s}$ for stations observed in the SE and NW direction, respectively. Their focal mechanism shows an average rake of $\sim 130^{\circ}$.

The two dynamic rupture scenarios differ slightly in moment magnitude, $M_{W} 5.63$ and $M_{W} 5.59$ for Model $1 \mathrm{~F}$ and Model $2 \mathrm{~F}$, reflecting different fault geometries while otherwise using 


\section{Palgunadi et al., 2020 BSSA Special Issue on Induced Seismicity PREPRINT}

the same model parameter selection. We point out that most slip of Model $2 \mathrm{~F}$ occurs on the main fault - its magnitude is reduced to $M_{W} 5.51$ when removing the subsidiary plane.

The resulting synthetic source time functions of Model 1F and Model 2F are presented in Figure $6 \mathrm{a}$ and $6 \mathrm{~b}$, respectively. The boxcar shaped moment rate function of Model $1 \mathrm{~F}$ results from its relatively simple rupture dynamics across one planar fault. Model $2 \mathrm{~F}$ features a more complicated moment rate function with two peaks of which the first one is reached at $t=0.5 \mathrm{~s}$ simulation time during simultaneous rupture of both fault planes. The rupture duration of each scenario is less than $1.5 \mathrm{~s}$ simulation time. The moment tensor representations of Model $1 \mathrm{~F}$ and Model 2F are presented in Figure 6c and 6d, respectively. Both scenarios show oblique faulting mechanisms. Model 1F clearly produces a double-couple moment tensor solution (Figure 6c), whereas the Model 2F yields a non-double couple solution due to complex source mechanism (Figure 6d), consistent with Grigoli et al. (2018). Nevertheless, our simulation produces a smaller amount of CLVD (compensated linear vector dipole) compared to Grigoli et al. (2018). The equivalent moment tensor solution of Model 2F can be decomposed, following the methodology of Vavryčuk (2015), into 82.95\% DC, -5.05\% CLVD, and -12\% isotropic (ISO) components. In contrast, Grigoli et al. (2018) find -37\% CLVD. In our simulations, Model 2F's rupture is characterized by an average rupture speed of $v_{r} \approx 2,250 \mathrm{~m} / \mathrm{s}$, well below the average Rayleigh wave speed at the depth of the faults $\left(v_{r} \approx 0.75 V_{S}\right)$. The spatial variation of $v_{r}$ is mainly related to the complexity of rupture around the intersection for both, the main and secondary fault plane. We observe higher average rupture speed $v_{r} \approx 2,780 \mathrm{~m} / \mathrm{s}\left(v_{r} \approx 0.8 V_{S}\right)$ on the secondary fault plane (see rupture contours every $0.2 \mathrm{~s}$ in Figures $5 \mathrm{~b}, 5 \mathrm{c}$ ). We note the localized occurrence of supershear rupture speed $(\sim 4000 \mathrm{~m} / \mathrm{s})$ near the edge of the prescribed nucleation patch of the main fault reflecting the high overstress required for initiating the preferred rupture dynamics in 


\section{Palgunadi et al., 2020 BSSA Special Issue on Induced Seismicity PREPRINT}

our setup. Also, the secondary fault plane features localized supershear episodes $(\sim 3800 \mathrm{~m} / \mathrm{s})$. In our model setup, this may be related to locally high fluid overpressure, and/or reflect the low resolution and 1D restriction of the used velocity model. More complex fluid effects have been shown to facilitate the transition to sub-rayleigh to supershear ruptures in fully coupled 2D models (Lin and Zoback, 2018).

In our preferred model, high slip ( $\sim 2 \mathrm{~m}$ ) occurs in the center of the main fault. We observe a maximum slip of $1.3 \mathrm{~m}$ at the secondary fault plane (Figure $7 \mathrm{~b}$ ). In total, the average on-fault slip is $0.32 \mathrm{~m}$. Model 1F and Model 2F both feature higher slip than Song and Lee (2019) infer in their static slip inversion. In addition, differences may arise due to different modeling assumptions in terms of fault dimensions and shear moduli. First, Song and Lee (2019) assume a slightly larger shear modulus of $G=30 \mathrm{GPa}$ than in our model $(G=26 \mathrm{GPa})$. Second, they assume a single fault plane of significantly larger dimensions $(6 \mathrm{~km} \times 5 \mathrm{~km})$ than the faults of our models (see Section Fault reconstruction). This large fault geometry allows for the possibility of near-surface slip.

The orientation of fault slip is modulated by the dynamic source process. The dynamic interaction of the two fault planes induces a moderate thrust-faulting component (rake $\sim 135^{\circ}-$ $150^{\circ}$ ) on the main fault plane, as well as complex time-dependent rake orientations on the secondary fault (see also Figure 7c, 7d). In contrast to Model 2F, the orientations of the final rake angle of Model 1F are distributed more homogeneously, with an average of $127^{\circ}$. The rake of Model $1 \mathrm{~F}$ is different from Model $2 \mathrm{~F}$ due to different dip angles of the main fault $\left(43^{\circ}\right.$ in Model 1F). This average rake angle is comparable to the focal mechanism derived by Grigoli et al. (2018) (rake of $130^{\circ}$ ). The average on-fault slip is $0.35 \mathrm{~m}$. We observe that, on average, the rupture speed is $v_{r} \approx 2400 \mathrm{~m} / \mathrm{s}$. Reflecting similar dynamic parameters to Model $2 \mathrm{~F}$, Model $1 \mathrm{~F}$ also experiences supershear rupture near the nucleation patch. 


\section{Palgunadi et al., 2020 BSSA Special Issue on Induced Seismicity PREPRINT}

\section{Waveform comparison for Model 1F and Model 2F}

In the following, we analyze the differences between Model $1 \mathrm{~F}$ and Model 2F in terms of near and far-field ground motion. Hereinafter, all distances from the fault are considered as JoynerBoore distances $\left(R_{J B}\right.$, the shortest distance from a site to the surface projection of fault planes). We compare synthetic waveforms computed for hypothetical ("virtual") stations located close ( 4 $\mathrm{km})$ and far $(>20 \mathrm{~km})$ from the epicenter.

Figure $8 \mathrm{~b}$ shows three-component waveforms at 19 randomly located virtual stations (Figure $8 \mathrm{a})$. We place 10 stations near the epicenter ( $4 \mathrm{~km}$ horizontal distance) to inspect nearfield seismic waveform characteristics. We filter all synthetic waveforms in the frequency band of $0.1-2 \mathrm{~Hz}$ using a $4^{\text {th }}$-order Butterworth filter. Figure $8 \mathrm{c}$ depicts all 3-component velocity waveforms. Overall, waveforms of Model $1 \mathrm{~F}$ and Model 2F are very similar in this frequency range, but waveforms from Model 1F have systematically higher amplitudes than Model 2F. The most remarkable amplitude differences occur on the EW component for stations 004, 008, 009, and 010 , which are all located above or close to the faults.

At some stations, distinct waveform differences appear (e.g., the NS-component of stations 007, 014, 011, and 019); these stations are mostly located on the hanging wall. After five seconds, once the rupture is fully arrested, differences vanish, and waveforms become comparable for both models. As depicted in Figure 8b, stations located close to the region where faults overlap in Model 2F show significant differences in seismic wave signatures on the horizontal components. We conjecture that the additional secondary fault defocuses ground motions and thus generates different waveforms. 


\section{Palgunadi et al., 2020 BSSA Special Issue on Induced Seismicity PREPRINT}

\section{Off-fault deformation}

Our preferred dynamic earthquake rupture model $2 \mathrm{~F}$ reveals significant off-fault plastic deformation in the vicinity of geometric fault complexity, similar to recent simulations for the 1992 Landers earthquake (Wollherr et al., 2018), the 2016 Kaikoura earthquake (Klinger et al., 2019) and the 2019 Ridgecrest earthquake sequence (Taufiqurrahman et al., 2019). Here, significant off-fault plastic deformation (quantified as the scalar quantity $\eta$ following Ma, 2008 and Wollherr et al., 2019) occurs (i) in the pre-existing damage zone at the fault intersection, (ii) at the dilatational side of the main and the secondary fault (as expected from previous theoretical and numerical studies, given the shallow angle of both faults and $S_{H \max }$; Templeton and Rice, 2008; Gabriel et al., 2013), and (iii) close to the free-surface (see Figures S4c and S4d).

The fault intersection of Model $2 \mathrm{~F}$ elevates the total off-fault plasticity response, diminishing high on-fault stresses while limiting peak slip rates and reducing peak ground motions (Andrews 2005; Dunham et al. 2011a; Gabriel et al., 2013; Roten et al., 2014; Wollherr et al., 2018). When comparing waveforms, we also notice overall lower velocity amplitudes (compared to Model 1F) on the near-fault stations caused by the combined effects of fault complexity and offfault yielding. Interestingly, the stronger plastic yielding response in Model $2 \mathrm{~F}$ leads to lower variability (not shown here) in ground motions (PGV) (as in Wollherr et al., 2019), even though the fault geometry is more complex.

\section{Model 1F and Model 2F surface deformations}

Next, we compare the co-seismic surface displacement generated by Model 1F to Model 2F (Figure 9a, 9b). We translate the synthetic vertical and horizontal displacements into Line-ofsight (LoS) displacement components. 


\section{Palgunadi et al., 2020 BSSA Special Issue on Induced Seismicity PREPRINT}

The spatial distribution of co-seismic surface deformation is noticeably different. Model 1F features higher LoS displacements in southeastern direction relative to the Gokgang Fault $(\sim 2$ $\mathrm{km}$ from the bay) compared to Model $2 \mathrm{~F}$ ( $\sim 5 \mathrm{~km}$ from the bay) and generates on average lower negative LoS displacements. Model 1F creates a wider area of uplifted LoS displacements, which resembles an ellipse with a major axis of $6 \mathrm{~km}$ and a minor axis of $4.1 \mathrm{~km}$. The most prominent spatial differences are (i) the vertical LoS displacements of Model 1F are slightly shifted to the East relative to the epicenter and (ii) the location of zero displacements in between positive LoS displacements (in the region of the epicenter) and negative LoS displacements at the eastern-tosouthward of the epicenter. Model 2F produces an average of $5 \mathrm{~cm}$ subsidence whereas Model $1 \mathrm{~F}$ only produces $2 \mathrm{~cm}$ average subsidence. This can be attributed to Model 1F's more shallow dipping angle. The co-seismic surface displacements of Model $2 \mathrm{~F}$ compare better to InSAR ground deformation inferences of Song and Lee (2019) than those of Model 1F in terms of the location of the pivot line delimiting positive and negative LoS displacements ( $\sim 4.5 \mathrm{~km}$ from the bay).

While synthetic (Model 2F) and observed surface displacements significantly differ locally and quantitatively, they reveal qualitatively comparable large-scale features. The following observations are captured by Model 2F: (i) uplift/eastward displacement is observed near the epicenter and (ii) the uplifted area forms an ellipse-like shape with a major axis of $\sim 5.6 \mathrm{~km}$ and a minor axis of $\sim 3.8 \mathrm{~km}$. Correspondingly, Pohang city also experienced subsidence according to field observations (Kang et al., 2019a, Kang et al., 2019b). Additionally, our synthetics also suggest subsidence underneath the bay.

Although the contribution of the secondary fault plane is critical to reproduce the inferred non-DC component, comparison of synthetic co-seismic surface displacements of Model 2F with and without the secondary fault (see Figure S5a) suggests that the contribution of the secondary 


\section{Palgunadi et al., 2020 BSSA Special Issue on Induced Seismicity PREPRINT}

fault plane to the ground displacement is small (Figure S5b), as expected from its small slip contribution. We note that the InSAR data may not be sensitive enough to discriminate between a one and a two-fault plane model.

\section{Model 2F validation by regional waveform modeling}

Unfortunately, a local seismic network of eight portable seismic stations (Kim et al., 2018) deployed around the EGS site produced saturated (clipped) seismograms. Therefore, we choose to compare synthetic waveforms to regional recordings at five stations surrounding the Pohang EGS site (see Figure 1) at epicentral distances of approximately more than $70 \mathrm{~km}$.

Synthetic seismograms for Model 2F compare well to corresponding regional lowfrequency seismic wave observations (Figure 8c). Synthetic waveforms are calculated using a Green's function database of teleseismic waveforms (Instaseis, Krischer et al., 2017). We transform the dynamic rupture model into a single moment tensor representation following Ulrich et al. (2019a, 2019b). The Green's function database we use is based on the anisotropic Preliminary Reference Earth Model (PREM), and is accurate to a minimum period of 2 s. Synthetic and observed waveforms are filtered in the frequency range $0.033-0.08 \mathrm{~Hz}$ using a fourth-order Butterworth filter, equivalent to the frequency band used in the source inversion of Grigoli et al. (2018). The goodness-of-fit is assessed by the root-mean-square (rms) misfit.

While the synthetic waveforms generally compare reasonably well to regional recordings, we find that synthetic amplitudes are larger than the observed data at few stations (e.g., NS components of station IU.INCN, KS.BUS2, KS.CHJ2, and KS.NAWB). We attribute this to the usage of a 1D PREM model, which is more suitable for modeling synthetics at larger azimuthal distance. Additionally, the fact that our simulation returns a slightly higher seismic moment than 


\section{Palgunadi et al., 2020 BSSA Special Issue on Induced Seismicity PREPRINT}

observed and is not able to fully capture non-DC components of the source may play a role. In addition, the large misfit at station KG.TJN on the UD and EW components may be attributed to unmodeled site effects. We quantitatively compare low-frequency $(0.033-0.08 \mathrm{~Hz})$ synthetics generated by a point source representing the dynamic rupture Model 2F to the ones corresponding to the inferred moment tensor solution of Grigoli et al. (2018) (see Figure S6). Our synthetics do not differ significantly from the synthetics of Grigoli et al. (2018) which are derived by fullwaveform inversion of the waveforms recorded at stations KS.BUS2, KS.CHJ2, and KS.NAWB. Notable differences are limited to the horizontal components of station KS.BUS2 and the vertical component of station KS.NAWB.

\section{Discussion}

\section{The importance of local stresses for rupture dynamics in EGS}

Previous studies examining stress regimes and maximum horizontal stress orientation around the Pohang EGS site provided varying interpretations, thereby motivating our systematic numerical experiments in Section Static and dynamic analysis of initial fault strength and stresses, considering various loading stress settings. Assuming a spatially uniform Andersonian stress regime, we find that an initial stress state constrained by regional stress inversions is unable to generate the observed thrust-faulting component of the Pohang earthquake. This suggests significant local deviations from the regional stress state near the Pohang EGS site. Kim et al. (2017) and Lee et al. (2017) infer the stress orientation at short epicentral distance $(<10 \mathrm{~km})$ from borehole image log data acquired prior to the Pohang earthquake. However, this data is limited to $1 \mathrm{~km}$ depth, whereas the Pohang earthquake hypocentral depth is much deeper, with an estimated 


\section{Palgunadi et al., 2020 BSSA Special Issue on Induced Seismicity PREPRINT}

depth of $4.27 \mathrm{~km}$. Ellsworth et al. (2019) note that the in-situ stress state at the Pohang EGS site is transpressional based on dipole sonic logging of the PX-2 well.

From our static numerical experiments, we infer that a pure strike-slip stress regime $\left(\sigma_{2}=\right.$ $S_{v}$ ) and $S_{H \max }=120^{\circ}$ yield a thrust-faulting component consistent with observations (Figure S2).

This finding is corroborated by our dynamic rupture simulations under identical loading (Figure 6c, 6d). We also observe that under these conditions spontaneous rupture propagation is favoured. In contrast, exploring also a reverse faulting regime $\left(\sigma_{3}=s_{v}\right)$ accounting for low $v=0.1$ across the entire fault planes, as suggested by Ellsworth et al. (2019), does not yield sufficiently high shear tractions on our fault system, leading to rapid cessation of dynamic rupture.

Local variations of the stress state around EGS sites, including the Pohang EGS site, have been observed in hydraulic stimulation experiments of crystalline-rock reservoirs (Schoenball et a., 2010), in data-driven geomechanical analysis (Ceunot et al., 2006; Hardebeck and Michael, 2006; Martínez-Garzón et al., 2013; Martínez-Garzón et al. 2014; Schoenball et al., 2014) and in numerical experiments (Jeanne et al., 2015; Ziegler et al., 2017). Such spatial and temporal stress reorientation is typically a direct response to hydraulic stimulation and fluid injections (Cornet et al., 2007; Schoenball et al., 2010; Schoenball et al., 2014; Ziegler et al., 2017, Liu and Zahradnik, 2019).

In the geothermal field surrounding the Geysers in California, Martínez-Garzón et al. (2014) found that the stress regime changed from normal-faulting to strike-slip near the injection wells. At the Pohang EGS site, local variations in the stress regime have been inferred from focal mechanisms of microearthquakes before and after the Pohang earthquake. Woo et al. (2019) reported strike-slip faulting north of the hypocenter to strike-slip associated thrust-faulting and pure thrust-faulting components towards the South before the mainshock. After the mainshock 


\section{Palgunadi et al., 2020 BSSA Special Issue on Induced Seismicity PREPRINT}

occurred, aftershock focal mechanisms were mainly strike-slip in the SW to oblique faulting in the NE (Kim et al., 2020). Changes in stress orientations and stress regime near the hypocenter prior to the mainshock are due to hydraulic stimulation and fluid injections (Martínez-Garzón et al., 2014; Liu and Zahradnik, 2019). Those changes may be related to elevated pore pressure and the corresponding changes in poroelastic stresses (Ceunot et al., 2006; Schoenball et al., 2014; Martínez-Garzón et al. 2014; Jeanne et al., 2015). Lim et al. (2020) evaluate the spatiotemporal changes in poroelastic stresses associated with fluid injection in the Pohang region and suggest that slow fluid diffusion could have resulted in Coulomb stress changes of up to 1.1 bar.

Based on the analysis of our numerical experiments, we deduce that our models are highly sensitive to variations in the initial stress state, and therefore allow for finely constraining the fault stress loading parameters. For example, a small change in $S_{H \max }$ may induce a significant change in the modeled focal mechanism. All faults are exposed to the same local stress regime while experiencing varying ratios of shear and normal loading, depending on their orientation towards this loading. Even a small change in fault geometry (e.g., in strike, dip, size, and the angle between fault planes) strongly affects the dynamic rupture result (e.g., Yamashita and Umeda, 1994; Aochi et al., 2005; Bhat et al., 2007; Ulrich et al., 2019a; van Zelst et al., 2019), as illustrated when comparing Model 1F and Model 2F. We point out that trade-offs between the inferred stress state and fault geometry can be readily explored if new observations become available.

As Model 2F comprises two intersecting fault planes with only small differences in strike and $\operatorname{dip}\left(15^{\circ}\right.$ in strike, $5^{\circ}$ in dip), both planes may be considered part of a single (wide) fault zone (e.g., Chester et al., 1993; Caine et al, 1996; Mitchell \& Faulkner, 2009). A large fraction of friable round-shape mud balls suggests a fault zone width of less than $200 \mathrm{~m}$ (Ellsworth et al., 2019), to be compared with a maximum distance of $\sim 750 \mathrm{~m}$ between the two faults of Model $2 \mathrm{~F}$. 


\section{Palgunadi et al., 2020 BSSA Special Issue on Induced Seismicity PREPRINT}

Complex volumetric failure patterns have been inferred for recent well-recorded small and large earthquakes (e.g., Cheng et al., 2018; Ross et al., 2019; Taufiqurrahman et al., 2019) and may be promoted by local stress perturbation. In our Model 2F, off-fault plastic deformation accumulates close to the fault intersection (Figure. S4) indicating that the local fault zone structure may be more complex than our Model 2F.

In summary, these observations support our assumption on the loading stress, which is consistent with Ellsworth et al. (2019) in the nucleation region, but differently oriented everywhere else. Complexities in the in-situ stress state are expected in the region where the Pohang earthquake occurred, due to the history of hydraulic stimulations. That is, the EGS operation itself perturbs the local stress conditions in a manner that makes it more difficult to assess the potential seismic hazard at the EGS site, while usually hazard assessment is conducted in advance utilizing the unperturbed regional stress information.

\section{The importance of critically stressed, static and dynamic weak faults and overpressurized fluids}

Our experiments (Figure 4) emphasize the necessity of assuming overpressurized fluids $(\gamma$ $>0.37)$ and a close to critical stress state. All models adopt rapid frictional weakening characterized by a large friction drop (Table A1). Fluid pressure, initial relative fault strength (parametrized by $R_{0}$ ) and friction drop jointly control the expected (dynamic) stress drop in each simulation. An a-priori order-of-magnitude estimate of stress drop can be written as: $R_{0}(1-\gamma) \sigma_{c}\left(\mu_{s}-\mu_{d}\right)$ (equation 18 in Ulrich et al. (2019a)), which highlights the interdependency of a realistic stress drop, strong dynamic weakening, fluid pressure,, and resolving sufficient shear tractions with the expected slip direction. 


\section{Palgunadi et al., 2020 BSSA Special Issue on Induced Seismicity PREPRINT}

A critically stressed state has been suggested by Ellsworth et al. (2019) by analyzing dipole sonic logging data at the Pohang drilling site. In our preferred Model 2F, we use the ratio of shear stress over effective normal stress $\left(\frac{\tau}{\sigma_{n}}\right)$ to quantify fault strength, and find ratios of 0.54 and 0.59 for the main and secondary fault plane, respectively. This fault strength is close to the assumed steady-state friction coefficient $\left(f_{0}=0.6\right)$, indicating that the faults are close to failure just prior to rupture nucleation and thus close to critically stressed.

In our preferred model, both faults are non-optimally oriented with respect to the local stress conditions. The relative prestress ratio is $R=0.35$ on the main fault and $R=0.4$ on the secondary fault plane, which is less than our assumed $R_{0}=0.8$. According to Andersonian faulting theory, the fault strength is related to its orientation with respect to the regional stress. Here, the main fault plane is oriented at $54^{\circ}$ and the secondary fault at $60^{\circ}$ relative to the regional maximum compressive stress $\left(S_{\text {Hmax }}=77^{\circ}\right)$. Thus, the two-fault system would be considered weak in the classic static sense.

All modeled faults in this study weaken dramatically at co-seismic slip rates while stress drops are limited by the elevated fluid pressure. Besides resembling the dramatic friction decrease observed in laboratory experiments and the theory of thermal weakening processes, previous dynamic rupture studies utilizing rapid velocity weakening using low values of fully weakened friction coefficient $\left(f_{w}\right)$ reproduced rupture complexities, such as rupture reactivation and pulselike ruptures, without assuming small-scale heterogeneities (e.g., Gabriel et al., 2012).

In our simulation, we use a fluid pressure ratio of $\gamma=0.5$ which corresponds to a reduction of the normal stress of approximately 14.3 MPa compared to a hydrostatic state. The reduction in effective normal stress mechanically lowers the static strength of faults. Our assumption of high fluid pressure may relate to various episodes of drilling mud loss (reported to have occurred on 


\section{Palgunadi et al., 2020 BSSA Special Issue on Induced Seismicity PREPRINT}

30-31 October 2015 at $3800 \mathrm{~m}$ depth), suggesting an increase of fluid pressure on the order of 20 $\mathrm{MPa}$ around the borehole, and the fluid injection operations (Ellsworth et al., 2019; Korean Government Commission, 2019).

\section{The importance of fault interaction for the dynamic rupture process and}

\section{faulting mechanism}

In our preferred model (Model $2 \mathrm{~F}$ ), the secondary fault only partially ruptured during the Pohang earthquake. Strong variations in slip rate associated with dynamic rupture complexity across the two faults planes and their interaction, spontaneous rupture arrest, and the asymmetrically accumulated fault slip on the main and secondary fault plane could potentially favor dynamic and static Coulomb stress transfers enabling a later activation of the unruptured area of the secondary fault. The largest aftershock (less than three hours after the mainshock at 650 m epicentral distance, northwest of the mainshock) may have occurred in such an unruptured area on the secondary fault.

In our model, complex shear faulting across two fault planes induces a non-DC component, which, however, is considerably smaller (14\%) compared to the CLVD component inferred by Grigoli et al. (2018). Additional factors not considered in this study may contribute to an apparent non-DC component, such as strong deviations from fault planarity (larger scale curvature and small-scale roughness, e.g., Bydlon and Dunham, 2015; Shi and Day, 2013; Ulrich et al, 2019c; Mai et al., 2018), stronger heterogeneities in fault stress and strength (Ripperger et al., 2008) and 3D subsurface structure (e.g., Pelties et al., 2015). However, rupture complexity is also increased when incorporating tensile faulting, poroelastic rheology, and source or propagation anisotropy (Julian, 1998; Boitz et al., 2018). The CLVD contribution may also increase when assuming a 


\section{Palgunadi et al., 2020 BSSA Special Issue on Induced Seismicity PREPRINT}

larger number of faults. While the limited data available does not suggest rupture of additional fault planes, stochastically distributed and dynamically activated fracture networks (e.g., Okubo et al. 2019; Anger and Gabriel, 2019) around the main fault are expected given the on-going stimulation operation.

\section{Importance of dense seismic monitoring during EGS projects}

The complex interaction of local stress loading and fault strength conditions, rupture dynamics and fault interaction on multiple fault segments presented here highlights the importance of and need for a dense local seismic network within the operational areas for monitoring and analyzing microseismicity before, during, and after EGS operation. Pre-EGS stimulation seismic monitoring is needed to define the 'unperturbed state' of the system (the rock volume to be stimulated) and for characterizing potentially unmapped fault(s) that may interact during cascading rupture; such seismic monitoring may be accompanied by detailed borehole logging to assess the local stress state prior to stimulation.

During the stimulation and operational phase, a dense seismic monitoring network is critically important to facilitate high-precision and high-fidelity seismic source studies (Kwiatek et al., 2019; Hillers et al., 2020). In conjunction with detailed operational fluid-injection parameters, the reservoir stress state and its susceptibility for generating earthquakes can be assessed (Galis et al., 2017; Kwiatek et al., 2019). The available recordings of the operational monitoring seismic network near the Pohang EGS site were saturated (clipped) by the unexpected high magnitude earthquake; therefore, we propose to install accelerometers as complementary instrumentation in EGS monitoring networks. In addition, the rise of Distributed Acoustic Sensing 


\section{Palgunadi et al., 2020 BSSA Special Issue on Induced Seismicity PREPRINT}

(DAS) opens new opportunities as an additional seismic monitoring network especially for EGS that is located in urban areas (Zhan, 2019).

Our study suggests that fully physics-based numerical simulations prior, during, and after an EGS project may be useful to not only gain a first-order understanding of potential effects and consequences of the EGS experiments (e.g., risk-prone area as reflected by peak ground motions (PGVs, Figure S7), but also to optimally design the seismic monitoring network to ensure that all vital data are collected as needed for future monitoring and mitigation purposes.

\section{Conclusions}

A guided fault reconstruction approach that clusters spatio-temporal aftershock locations accounting for their uncertainty is applied to create the geometry for a dynamic rupture model that comprises two fault planes and that reproduces key characteristics of the Pohang earthquake. Rupture complexity is arising from the dynamic interaction of two failing fault planes with shallow intersection angles.

Static Mohr-Coulomb failure analysis and 180 numerical simulations demonstrate that the regional loading stress is unable to generate dynamic rupture consistent with the observed faulting style. Resolving the regional tectonic stress field onto a single-fault plane with a geometry as suggested by Korean Government Commission (2019), Ellsworth et al. (2019), and Woo et al. (2019), or onto the reconstructed two fault planes, leads inevitable to pure strike-slip faulting, in stark contrast to the observed thrust-faulting mechanism. Instead, local stress variation relative to regional stress orientation is needed to generate oblique faulting. We conclude that regional-stress orientation may be misleading when assessing propensity for failure, this has important implications for seismic hazard assessment. Also, overpressurized pore fluids, non-optimally 


\section{Palgunadi et al., 2020 BSSA Special Issue on Induced Seismicity PREPRINT}

oriented and dynamically weak faults and a close to critical local stress state play major roles for our dynamic rupture models of the Pohang earthquake. Such factors may be assessed when planning and conducting EGS-type experiments, explorations, and operations.

Our dynamic rupture simulations reveal dynamic triggering from the main fault plane to the secondary fault plane without direct rupture branching but via "rupture jumping". Model $2 \mathrm{~F}$ simulation compares well to regional observed data such as moment release and far-field seismic waveforms. Model 1F, on the other hand, is unable to reproduce the observed non-DC focal mechanisms and surface displacement distributions due to simplicity of the dynamic rupture process and a shallower dip angle, respectively. Dynamic fault interaction, amplified by rapid stress changes due to seismic waves reverberating between the two fault planes, are needed to reproduce observations of a strong CLVD component. However, two simultaneously breaking fault planes cannot fully explain the observed source complexity.

We demonstrate the maturity and feasibility of high-resolution 3D modeling of rupture dynamics and seismic wave propagation accounting for the complexity of EGS environments and constrained by few observational parameters shedding light on the dynamics of induced and triggered earthquakes. More sophisticated 3D models, fully coupling dynamic earthquake rupture and seismic wave propagation with co-seismic and quasi-static fluid effects, such as poroelasticity, thermal pressurization, pore pressure diffusion, and considering the geometric complexity of networks of fractures and non-planar faults, will allow capturing the full physical complexity of nucleation and dynamics of induced earthquakes.

In the near future, such physics-based approaches may be synergistically integrated with near-field seismic monitoring before, during, and after EGS operation, thus complementing traffic light systems for hazard and risk mitigation (Bommer et al., 2006; Mignan et al., 2015). 


\section{Palgunadi et al., 2020 BSSA Special Issue on Induced Seismicity PREPRINT}

\section{Data and resources}

The open-source software package SeisSol can be downloaded in github repository (https://github.com/SeisSol/SeisSol). The procedure to download, compile and execute the code is described in the documentation (https://seissol.readthedocs.io/en/latest/). All regional waveforms used in this study were downloaded from Incorporated Research Institutions for Seismology (IRIS; https://www.iris.edu (last accessed February 2020)) data management system using FDSN client. PREM anisotropic $2 \mathrm{~s}$ can be downloaded in the IRIS data services products (http://ds.iris.edu/ds/products/syngine/ (last accessed February 2020)). The supplemental for this article provides additional figures, a table, all parameters used for the preferred Model 2F, and a video mentioned in the article.

\section{Acknowledgments}

We thank Xing Li and Prof. Sigurjón Jónsson for the discussions regarding surface deformations using InSAR. We also thank Prof. Guy Ouillon for providing us the raw code of ACLUD. We acknowledge Dr. Seok Goo Song and Prof. Hoonyol Lee for sharing the processed InSAR images and discussions about inversion parameters. We thank the Guest Editor, two anonymous reviewers and Betty Schiefelbein for their insightful comments and constructive suggestions. Computing resources were provided by King Abdullah University of Science and Technology, Thuwal, Saudi Arabia (KAUST, project k1219 and k1343 on Shaheen II). The work presented in this paper was supported by KAUST grants (FRAGEN, ORS-2017-CRG6 3389.02, URF/1/3389-01-01, and BAS/1339-01-01. A.-A.G. and T.U. acknowledge support by the European Research Council 


\section{Palgunadi et al., 2020 BSSA Special Issue on Induced Seismicity PREPRINT}

European under the European Union's Horizon 2020 research and innovation programme (TEAR, grant no. 852992 and ChEESE, grant no. 823844) and the German Research Foundation (DFG) (projects GA 2465/2-1, GA 2465/3-1) and by KONWIHR - the Bavarian Competence Network for Technical and Scientific High Performance Computing (project NewWave). J.A.L-C has also received funding from the European Union's Horizon 2020 research and innovation programme under the Marie Skłodowska-Curie grant agreement $\mathrm{N}^{\circ} 754446$ and UGR Research and Knowledge Transfer Found - Athenea3i; and by the Deutsche Forschungsgemeinschaft (DFG,

German Research Foundation) - Projektnummer (407141557). Part of the analysis was implemented using ObsPy (Beyreuther et al., 2010). Figures were prepared using Paraview (Ahrens et al., 2005), Generic Mapping Tools (Wessel et al., 2013) and Matplotlib (Hunter, 2007)

\section{References}

Ahrens, J., B. Geveci, and C. Law, 2005, ParaView: An end-user tool for large-data visualization, in Visualization Handbook, Elsevier Inc., 717-731.

Ando, R., and Y. Kaneko, 2018, Dynamic Rupture Simulation Reproduces Spontaneous Multifault Rupture and Arrest During the 2016 Mw 7.9 Kaikoura Earthquake, Geophys. Res. Lett., 45, no. 23, 12,875-12,883, doi: 10.1029/2018GL080550.

Andrews, D. J., 2005, Rupture dynamics with energy loss outside the slip zone, J. Geophys. Res., 110, no. B1, B01307, doi: 10.1029/2004JB003191.

Anger, S. and A.-A Gabriel (2019). Dynamic earthquake rupture across complex 3D fracture networks. S55E-0444 presented at the 2019 Fall Meeting, AGU, San Francisco, CA, 9-13 


\section{Palgunadi et al., 2020 BSSA Special Issue on Induced Seismicity PREPRINT}

Dec.

Aochi, H., and R. Madariaga, 2003, The 1999 Izmit, Turkey, earthquake: Nonplanar fault structure, dynamic rupture process, and strong ground motion, Bull. Seismol. Soc. Am., 93, no. 3, 1249-1266, doi: 10.1785/0120020167.

Aochi, H., O. Scotti, and C. Berge-Thierry, 2005, Dynamic transfer of rupture across differently oriented segments in a complex 3-D fault system, Geophys. Res. Lett., 32, no. 21, L21304, doi: 10.1029/2005GL024158.

Bauer, A., Scheipl, F., Küchenhoff, H., and Gabriel, A.-A. (2018). An introduction to semiparametric function-on-scalar regression. Statistical Modelling, 18(3-4), 346-364. https://doi.org/10.1177/1471082X17748034.

Beyreuther, M., R. Barsch, L. Krischer, T. Megies, Y. Behr, and J. Wassermann, 2010, ObsPy: A python toolbox for seismology, Seismol. Res. Lett., 81, no. 3, 530-533, doi: 10.1785/gssrl.81.3.530.

Bhat, H. S., M. Olives, R. Dmowska, and J. R. Rice, 2007, Role of fault branches in earthquake rupture dynamics, J. Geophys. Res., 112, no. B11, B11309, doi: 10.1029/2007JB005027.

Boitz, N., A. Reshetnikov, and S. A. Shapiro, 2018, Visualizing effects of anisotropy on seismic moments and their potency-tensor isotropic equivalent, Geophysics, 83, no. 3, C85-C97, doi: 10.1190/geo2017-0442.1.

Bommer, J.J., Oates, S., Cepeda, J.M., Lindholm, C., Bird, J., Torres, R., Marroquín, G. and Rivas, J., 2006. Control of hazard due to seismicity induced by a hot fractured rock 


\section{Palgunadi et al., 2020 BSSA Special Issue on Induced Seismicity PREPRINT}

geothermal project. Engineering Geology, 83(4), pp.287-306.

Breuer, A., A. Heinecke, and M. Bader, 2016, Petascale Local Time Stepping for the ADER-DG Finite Element Method, in Proceedings - 2016 IEEE 30th International Parallel and Distributed Processing Symposium, IPDPS 2016, Institute of Electrical and Electronics Engineers Inc., 854-863.

Breuer, A., A. Heinecke, S. Rettenberger, M. Bader, A.-A. Gabriel, and C. Pelties, 2014, Sustained Petascale Performance of Seismic Simulations with SeisSol on SuperMUC, 1-18.

Bydlon, S. A., and E. M. Dunham, 2015, Rupture dynamics and ground motions from earthquakes in 2-D heterogeneous media, Geophys. Res. Lett., 42, no. 6, 1701-1709, doi: 10.1002/2014GL062982.

Caine, J. S., J. P. Evans, and C. B. Forster, 1996, Fault zone architecture and permeability structure, Geology, 24, no. 11, 1025-1028, doi: 10.1130/00917613(1996)024<1025:fzaaps $>2.3 . c 0 ; 2$

Cappa, F., and J. Rutqvist, 2012, Seismic rupture and ground accelerations induced by CO 2 injection in the shallow crust, Geophys. J. Int., 190, no. 3, 1784-1789, doi: 10.1111/j.1365246X.2012.05606.x.

Chang, K. W., H. Yoon, Y. Kim, and M. Y. Lee, 2020, Operational and geological controls of coupled poroelastic stressing and pore-pressure accumulation along faults: Induced earthquakes in Pohang, South Korea, Sci. Rep., 10, no. 1, 2073, doi: 10.1038/s41598-02058881-z. 


\section{Palgunadi et al., 2020 BSSA Special Issue on Induced Seismicity PREPRINT}

Cheng, Y., and X. Chen, 2018, Characteristics of seismicity inside and outside the salton sea geothermal field, Bull. Seismol. Soc. Am., 108, no. 4, 1877-1888, doi: $10.1785 / 0120170311$.

Cheng, Y., Z. E. Ross, and Y. Ben-Zion, 2018, Diverse Volumetric Faulting Patterns in the San Jacinto Fault Zone, J. Geophys. Res. Solid Earth, doi: 10.1029/2017JB015408.

Chester, F. M., Evans, J. P., and Biegel, R. L., 1993, Internal structure and weakening mechanisms of the San Andreas fault: J. Geophys. Res., v. 98, p. 771-786.

Choi, J. H., K. Ko, Y. S. Gihn, C. S. Cho, H. Lee, S. G. Song, E. S. Bang, H. J. Lee, H. K. Bae, S. W. Kim et al., 2019, Surface deformations and rupture processes associated with the 2017 Mw 5.4 Pohang, Korea, earthquake, Bull. Seismol. Soc. Am., 109, no. 2, 756-769, doi: $10.1785 / 0120180167$.

Cornet, F.H., T. Bérard, and S. Bourouis, 2007. How close to failure is a granite rock mass at a 5 km depth?. International Journal of Rock Mechanics and Mining Sciences, 44(1), pp.47-66.

Cuenot, N., J. Charléty, L. Dorbath, and H. Haessler, 2006, Faulting mechanisms and stress regime at the European HDR site of Soultz-sous-Forêts, France, Geothermics, 35, nos. 5-6, 561-575, doi: 10.1016/j.geothermics.2006.11.007.

Dieterich, J. H., K. B. Richards-Dinger, and K. A. Kroll, 2015, Modeling injection-induced seismicity with the physics-based earthquake simulator RSQSim, Seismol. Res. Lett., 86, no. 4, 1102-1109, doi: 10.1785/0220150057.

Duan, B., 2016, Spontaneous rupture on natural fractures and seismic radiation during hydraulic 


\section{Palgunadi et al., 2020 BSSA Special Issue on Induced Seismicity PREPRINT}

fracturing treatments, Geophys. Res. Lett., 43, no. 14, 7451-7458, doi:

10.1002/2016GL069083.

Dumbser, M., and M. Käser, 2006, An arbitrary high-order discontinuous Galerkin method for elastic waves on unstructured meshes - II. The three-dimensional isotropic case, Geophys. J. Int., 167, no. 1, 319-336, doi: 10.1111/j.1365-246X.2006.03120.x.

Dunham, E. M., D. Belanger, L. Cong, and J. E. Kozdon, 2011a, Earthquake ruptures with strongly rate-weakening friction and off-fault plasticity, part 1: Planar faults, Bull. Seismol. Soc. Am., 101, no. 5, 2296-2307, doi: 10.1785/0120100075.

Dunham, E. M., D. Belanger, L. Cong, and J. E. Kozdon, 2011b, Earthquake ruptures with strongly rate-weakening friction and off-fault plasticity, part 2: Nonplanar faults, Bull. Seismol. Soc. Am., 101, no. 5, 2308-2322, doi: 10.1785/0120100076.

Ellsworth, W. L., D. Giardini, J. Townend, S. Ge, and T. Shimamoto, 2019, Triggering of the Pohang, Korea, Earthquake (Mw 5.5) by enhanced geothermal system stimulation, Seismological Society of America, 1844-1858.

Emerson paradigm holding, 2018, GoCad: A computer aided design program for geological applications.

Gabriel, A.-A., J.-P. Ampuero, L. A. Dalguer, and P. M. Mai, 2012, The transition of dynamic rupture styles in elastic media under velocity-weakening friction. J. Geophys. Res. Solid Earth, 117, no. B9.

Gabriel, A.-A., J.-P. Ampuero, L. A. Dalguer, and P. M. Mai, 2013, Source properties of 


\section{Palgunadi et al., 2020 BSSA Special Issue on Induced Seismicity PREPRINT}

dynamic rupture pulses with off-fault plasticity, J. Geophys. Res. Solid Earth, 118, no. 8, 4117-4126, doi: 10.1002/jgrb.50213.

Galis, M., J. P. Ampuero, P. M. Mai, and F. Cappa, 2017, Induced seismicity provides insight into why earthquake ruptures stop, Sci. Adv., 3, no. 12, doi: 10.1126/sciadv.aap7528.

Gallovič, F., Valentová, L., Ampuero, J.-P., and Gabriel, A.-A. , 2019a. Bayesian dynamic finitefault inversion: 1. Method and synthetic test. J. Geophys. Res., 124, 6949-6969. https://doi.org/10.1029/2019JB017510

Gallovič, F., Valentová, L., Ampuero, J.-P., and Gabriel, A.-A., 2019b. Bayesian Dynamic Finite-Fault Inversion: 2. Application to the 2016 Mw6.2 Amatrice, Italy, Earthquake, J. Geophys. Res., doi:10.1029/2019JB017512.

Garagash, D. I., and L. N. Germanovich, 2012, Nucleation and arrest of dynamic slip on a pressurized fault, J. Geophys. Res. B Solid Earth, 117, no. 10, doi: 10.1029/2012JB009209.

Grigoli, F., S. Cesca, A. P. Rinaldi, A. Manconi, J. A. López-Comino, J. F. Clinton, R. Westaway, C. Cauzzi, T. Dahm, and S. Wiemer, 2018, The November 2017 M w 5.5 Pohang earthquake: A possible case of induced seismicity in South Korea, Science (80-. )., 360, no. 6392, 1003-1006, doi: 10.1126/science.aat2010.

Happ, C., Scheipl, F., A.-A. Gabriel, S. Greven, 2019, A general framework for multivariate functional principal component analysis of amplitude and phase variation. Stat. 2019; 8:e220. https://doi.org/10.1002/sta4.220

Hardebeck, J. L., and A. J. Michael, 2006, Damped regional-scale stress inversions: 


\section{Palgunadi et al., 2020 BSSA Special Issue on Induced Seismicity PREPRINT}

Methodology and examples for southern California and the Coalinga aftershock sequence, J. Geophys. Res. Solid Earth, 111, no. B11, doi: 10.1029/2005JB004144.

Harris, R. A., M. Barall, B. Aagaard, S. Ma, D. Roten, K. Olsen, B. Duan, D. Lie, B. Luo, K. Bai et al., 2018, A suite of exercises for verifying dynamic earthquake rupture codes, Seismol. Res. Lett., 89, no. 3, 1146-1162, doi: 10.1785/0220170222.

Harris, R. A., M. Barall, D. J. Andrews, B. Duan, S. Ma, E. M. Dunham, A.-A. Gabriel, Y. Kaneko, Y. Kase, B. T. Aagaard et al., 2011, Verifying a Computational Method for Predicting Extreme Ground Motion, Seismol. Res. Lett., 82, no. 5, 638-644, doi: 10.1785/gssrl.82.5.638.

Heidbach, O. M. Rajabi, X. Cui, K. Fuchs, B. Muller, J. Reinecker, K. Reiter, M. Tingay, F. Wenzel, F. Xie, et al., 2018, The World Stress Map database release 2016: Crustal stress pattern across scales, Elsevier B.V., 484-498.

Heinecke, A., A. Breuer, S. Retenberger, M. Bader, A.-A. Gabriel, C. Pelties, A. Bode, W. Barth, X. Liao, K. Vaidyanathan, et al., 2014, Petascale High-Order Dynamic Rupture Earthquake Simulations on Heterogeneous Supercomputers, in International Conference for High Performance Computing, Networking, Storage and Analysis, SC, IEEE Computer Society, 3-14.

Hillers, G., T. A. T. Vuorinen, M. R. Uski, J. T. Kortström, P. B. Mäntyniemi, T. Tiira, P. E. Malin, and T. Saarno, 2020, The 2018 Geothermal Reservoir Stimulation in Espoo/Helsinki, Southern Finland: Seismic Network Anatomy and Data Features, Seismol. Res. Lett., 91, no. 2A, 770-786, doi: 10.1785/0220190253. 


\section{Palgunadi et al., 2020 BSSA Special Issue on Induced Seismicity PREPRINT}

Hirata, T., 1989, Fractal dimension of fault systems in Japan: Fractal structure in rock fracture geometry at various scales, Pure Appl. Geophys. PAGEOPH, 131, nos. 1-2, 157-170, doi: 10.1007/BF00874485.

Hofmann, H., G. Zimmermann, M. Farkas, E. Huenges, A. Zang, M. Leonhardt, G. Kwiatek, P. Martinez-Garzon, M. Bohnhoff, K. B. Min et al., 2019, First field application of cyclic soft stimulation at the Pohang Enhanced Geothermal System site in Korea, Geophys. J. Int. (2019) 217, 926-949

Hunter, J. D., 2007, Matplotlib: A 2D graphics environment, Comput. Sci. Eng., 9, no. 3, 99104, doi: 10.1109/MCSE.2007.55.

Jeanne, P., J. Rutqvist, P. F. Dobson, J. Garcia, M. Walters, C. Hartline, and A. Borgia, 2015, Geomechanical simulation of the stress tensor rotation caused by injection of cold water in a deep geothermal reservoir, J. Geophys. Res. Solid Earth, 120, no. 12, 8422-8438, doi: 10.1002/2015JB012414.

Jin, L., and M. D. Zoback, 2018, Fully Dynamic Spontaneous Rupture Due to Quasi-Static Pore Pressure and Poroelastic Effects: An Implicit Nonlinear Computational Model of FluidInduced Seismic Events, J. Geophys. Res. Solid Earth, 123, no. 11, 9430-9468, doi: 10.1029/2018JB015669.

Julian, B. R., A. D. Miller, and G. R. Foulger, 1998, Non-double-couple earthquakes 1. Theory, Rev. Geophys., 36, no. 4, 525-549, doi: 10.1029/98RG00716.

Kang, S., B. Kim, S. Bae, H. Lee, and M. Kim, 2019a, Earthquake-Induced Ground Deformations in the Low-Seismicity Region: A Case of the 2017 M5.4 Pohang, South 


\section{Palgunadi et al., 2020 BSSA Special Issue on Induced Seismicity PREPRINT}

Korea, Earthquake, Earthq. Spectra, 35, no. 3, 1235-1260, doi: 10.1193/062318EQS160M.

Kang, S., B. Kim, H. Cho, J. Lee, K. Kim, S. Bae, and C. Sun, 2019b, Ground-Motion Amplifications in Small-Size Hills: Case Study of Gokgang-ri, South Korea, during the 2017 ML 5.4 Pohang Earthquake Sequence, Bull. Seismol. Soc. Am., 109, no. 6, 26262643, doi: 10.1785/0120190064.

Käser, M., and M. Dumbser, 2006, An arbitrary high-order discontinuous Galerkin method for elastic waves on unstructured meshes - I. The two-dimensional isotropic case with external source terms, Geophys. J. Int., 166, no. 2, 855-877, doi: 10.1111/j.1365246X.2006.03051.x.

Kim, K. H., J. H. Ree, Y. H. Kim, S. Kim, S. Y. Kang, and W. Seo, 2018, Assessing whether the 2017 Mw5.4 Pohang earthquake in South Korea was an induced event, Science (80-. )., 360, no. 6392, 1007-1009, doi: 10.1126/science.aat6081.

Kim, K. H., W. Seo, J. Han, J. Kwon, S. Y. Kang, J. H. Ree, S. Kim, and K. Liu, 2020, The 2017 ML 5.4 Pohang earthquake sequence, Korea, recorded by a dense seismic network, Tectonophysics, 774, doi: 10.1016/j.tecto.2019.228306.

Kim, H., L. Xie, K. B. Min, S. Bae, and O. Stephansson, 2017, Integrated In Situ Stress Estimation by Hydraulic Fracturing, Borehole Observations and Numerical Analysis at the EXP-1 Borehole in Pohang, Korea, Rock Mech. Rock Eng., 50, no. 12, 3141-3155, doi: 10.1007/s00603-017-1284-1.

Klinger, Y., K. Okubo, A. Vallage, J. Champenois, A. Delorme, E. Rougier, Z. Lei, E. E. Knight, A. Munjiza, C. Satriano, et al., 2018, Earthquake Damage Patterns Resolve Complex 


\section{Palgunadi et al., 2020 BSSA Special Issue on Induced Seismicity PREPRINT}

Rupture Processes, Geophys. Res. Lett., 45, no. 19, 10,279-10,287, doi: 10.1029/2018GL078842.

Korean Government Commission, 2019, Summary Report of the Korean Government Commission on Relations between the 2017 Pohang Earthquake and EGS Project.

Krischer, L., A. R. Hutko, M. Van Driel, S. Stähler, M. Bahavar, C. Trabant, and T. NissenMeyer, 2017, On-demand custom broadband synthetic seismograms, Seismol. Res. Lett., 88, no. 4, 1127-1140, doi: 10.1785/0220160210.

Kroll, K. A., K. B. Richards-Dinger, and J. H. Dieterich, 2017, Sensitivity of Induced Seismic Sequences to Rate-and-State Frictional Processes, J. Geophys. Res. Solid Earth, 122, no. 12, 10,207-10,219, doi: 10.1002/2017JB014841.

Kwiatek, G., T. Saarno, T. Ader, F. Bluemle, M. Bohnhoff, M. Chendorain, G. Dresen, P. Heikkinen, I. Kukkonen, P. Leary et al., 2019, Controlling fluid-induced seismicity during a 6.1-km-deep geothermal stimulation in Finland, Sci. Adv., 5, no. 5, eaav7224, doi: 10.1126/sciadv.aav7224.

Kyriakopoulos, C., D. D. Oglesby, T. K. Rockwell, A. J. Meltzner, M. Barall, J. M. Fletcher, and D. Tulanowski, 2019, Dynamic Rupture Scenarios in the Brawley Seismic Zone, Salton Trough, Southern California, J. Geophys. Res. Solid Earth, 124, no. 4, 3680-3707, doi: 10.1029/2018JB016795.

de la Puente, J., J.-P. Ampuero, and M. Käser, 2009, Dynamic rupture modeling on unstructured meshes using a discontinuous Galerkin method, J. Geophys. Res., 114, no. B10, B10302, doi: 10.1029/2008JB006271. 


\section{Palgunadi et al., 2020 BSSA Special Issue on Induced Seismicity PREPRINT}

Lee, K. K., W. L. Ellsworth, D. Giardini, J. Townend, S. Ge, T. Shimamoto, I. W. Yeo, T. S. Kang, J. Rhie, D. G. Sheen et al., 2019, Managing injection-induced seismic risks, Science, 364, no. 6442, 730-732, doi: 10.1126/science.aax 1878 .

Lee, J., T. K. Hong, and C. Chang, 2017, Crustal stress field perturbations in the continental margin around the Korean Peninsula and Japanese islands, Tectonophysics, 718, 140-149, doi: 10.1016/j.tecto.2017.08.003.

Lee, H., Y. J. Shinn, S. H. Ong, S. W. Woo, K. G. Park, T. J. Lee, and S. W. Moon, 2017, Fault reactivation potential of an offshore CO2 storage site, Pohang Basin, South Korea, J. Pet. Sci. Eng., 152, 427-442, doi: 10.1016/j.petrol.2017.03.014.

Liu, J. and Zahradník, J., The 2019 MW 5.7 Changning earthquake, Sichuan Basin, China-a shallow doublet with different faulting styles. Geophys. Res. Let., p.e2019GL085408.

Lim, H., K. Deng, Y. H. Kim, J. -H. Ree, T. -R. A. Song, and K. -H. Kim, 2020, The 2017 Mw 5.5 Pohang earthquake, South Korea, and poroelastic stress changes associated with fluid injection, J. Geophys. Res. Solid Earth, doi: 10.1029/2019jb019134.

Ma, S., 2008, A physical model for widespread near-surface and fault zone damage induced by earthquakes. Geochemistry, Geophysics, Geosystems, $9(11)$.

Mai, P. M., M. Galis, K. K. S. Thingbaijam, J. C. Vyas, and E. M. Dunham, 2018, Accounting for Fault Roughness in Pseudo-Dynamic Ground-Motion Simulations, Birkhäuser, Cham, $95-126$.

Martínez-Garzón, P., M. Bohnhoff, G. Kwiatek, and G. Dresen, 2013, Stress tensor changes 


\section{Palgunadi et al., 2020 BSSA Special Issue on Induced Seismicity PREPRINT}

related to fluid injection at The Geysers geothermal field, California, Geophys. Res. Lett., 40, no. 11, 2596-2601, doi: 10.1002/grl.50438.

Martínez-Garzón, P., G. Kwiatek, H. Sone, M. Bohnhoff, G. Dresen, and C. Hartline, 2014, Spatiotemporal changes, faulting regimes, and source parameters of induced seismicity: A case study from The Geysers geothermal field, J. Geophys. Res. Solid Earth, 119, no. 11, 8378-8396, doi: 10.1002/2014JB011385.

McGarr, A., 2014, Maximum magnitude earthquakes induced by fluid injection, J. Geophys. Res. Solid Earth, 119, no. 2, 1008-1019, doi: 10.1002/2013JB010597.

Mitchell, T. M., and D. R. Faulkner, 2009, The nature and origin of off-fault damage surrounding strike-slip fault zones with a wide range of displacements: A field study from the Atacama fault system, northern Chile, J. Struct. Geol., doi: 10.1016/j.jsg.2009.05.002.

Mignan, A., Landtwing, D., Kästli, P., Mena, B. and Wiemer, S., 2015. Induced seismicity risk analysis of the 2006 Basel, Switzerland, Enhanced Geothermal System project: Influence of uncertainties on risk mitigation. Geothermics, 53, pp.133-146.

Okubo, K., H. S. Bhat, E. Rougier, S. Marty, A. Schubnel, Z. Lei, E. E. Knight, and Y. Klinger, 2019, Dynamics, Radiation, and Overall Energy Budget of Earthquake Rupture With Coseismic Off-Fault Damage, J. Geophys. Res. Solid Earth, 124, no. 11, 11771-11801, doi: 10.1029/2019JB017304.

Pelties, C., A.-A. Gabriel, and J.-P. Ampuero, 2014, Verification of an ADER-DG method for complex dynamic rupture problems, Geosci. Model Dev., 7, no. 3, 847-866, doi: 10.5194/gmd-7-847-2014 and Geoscientific Model Development Discussions, 6(4), 5981-- 


\section{Palgunadi et al., 2020 BSSA Special Issue on Induced Seismicity PREPRINT}

6034, doi:10.5194/gmdd-6-5981-2013.

Pelties, C., Y. Huang, and J. P. Ampuero, 2015, Pulse-Like Rupture Induced by ThreeDimensional Fault Zone Flower Structures, Pure Appl. Geophys., 172, no. 5, 1229-1241, doi: 10.1007/s00024-014-0881-0.

Pelties, C., J. de la Puente, J.-P. Ampuero, G. B. Brietzke, and M. Käser, 2012, Threedimensional dynamic rupture simulation with a high-order discontinuous Galerkin method on unstructured tetrahedral meshes, J. Geophys. Res. Solid Earth, 117, no. B2, n/a-n/a, doi: 10.1029/2011JB008857.

Peyrat, S., K. Olsen, and R. Madariaga, 2001, Dynamic modeling of the 1992 Landers earthquake, J. Geophys. Res. Solid Earth, 106, no. B11, 26467-26482, doi: 10.1029/2001jb000205.

Rettenberger, S., O. Meister, M. Bader, and A.-A. Gabriel, 2016, ASAGI - A parallel server for adaptive geoinformation, EASC '16: Proceedings of the Exascale Applications and Software Conference 2016, April 2016, Article No.: 2, Pages 1-9, https://doi.org/10.1145/2938615.2938618.

Richards-Dinger, K., and J. H. Dieterich, 2012, RSQSim earthquake simulator, Seismol. Res. Lett., 83, no. 6, 983-990, doi: 10.1785/0220120105.

Ripperger, J., Mai, P.M. and Ampuero, J.P., 2008. Variability of near-field ground motion from dynamic earthquake rupture simulations. Bulletin of the seismological society of America, 98(3), pp.1207-1228. 


\section{Palgunadi et al., 2020 BSSA Special Issue on Induced Seismicity PREPRINT}

Ross, Z. E. et al., 2019, Hierarchical interlocked orthogonal faulting in the 2019 Ridgecrest earthquake sequence, Science (80-. )., doi: 10.1126/science.aaz0109.

Roten, D., K. B. Olsen, S. M. Day, Y. Cui, and D. Fäh, 2014, Expected seismic shaking in Los Angeles reduced by San Andreas fault zone plasticity, Geophys. Res. Lett., 41, no. 8, 27692777, doi: 10.1002/2014GL059411.

Schoenball, M., L. Dorbath, E. Gaucher, J. F. Wellmann, and T. Kohl, 2014, Change of stress regime during geothermal reservoir stimulation, Geophys. Res. Lett., 41, no. 4, 1163-1170, doi: 10.1002/2013GL058514.

Schoenball, M., T. M. Müller, B. I. R. Müller, and O. Heidbach, 2010, Fluid-induced microseismicity in pre-stressed rock masses, Geophys. J. Int., 180, no. 2, 813-819, doi: 10.1111/j.1365-246X.2009.04443.x.

Shi, Z., and S. M. Day, 2013, Rupture dynamics and ground motion from 3-D rough-fault simulations, J. Geophys. Res. Solid Earth, 118, no. 3, 1122-1141, doi: 10.1002/jgrb.50094.

Simmetrix Inc, 2017, SimModeler: Simulation modeling suite 14.0 documentation (Tech. Rep.).

Soh, I., C. Chang, J. Lee, T.-K. Hong, and E.-S. Park, 2018, Tectonic stress orientations and magnitudes, and friction of faults, deduced from earthquake focal mechanism inversions over the Korean Peninsula, Geophys. J. Int., 213, no. 2, 1360-1373, doi: 10.1093/gji/ggy061.

Song, S. G., and H. Lee, 2019, Static slip model of the 2017 M w 5.4 Pohang, South Korea, earthquake constrained by the InSAR data, Seismol. Res. Lett., 90, no. 1, 140-148, doi: 


\section{Palgunadi et al., 2020 BSSA Special Issue on Induced Seismicity PREPRINT}

$10.1785 / 0220180156$.

Di Toro, G., R. Han, T. Hirose, N. De Paola, S. Nielsen, K. Mizoguchi, F. Ferri, M. Cocco, and T. Shimamoto, 2011, Fault lubrication during earthquakes, Nature, 471, no. 7339, 494-499, doi: $10.1038 /$ nature09838.

Taufiqurrahman, T., A.-A. Gabriel, B. Li, D. Li, S. A. Wirp, T. Ulrich, K. H. Palgunadi, A. Verdecchia, S. Carena, and Z. K. Mildon, 2019, High-resolution integrated dynamic rupture modeling of the 2019 M6. 4 Searles Valley and M7. 1 Ridgecrest earthquakes. S31G-0487 presented at the 2019 Fall Meeting, AGU, San Francisco, CA, 9-13 Dec.

Templeton, E.L. and Rice, J.R., 2008. Off-fault plasticity and earthquake rupture dynamics: 1. Dry materials or neglect of fluid pressure changes. J. Geophys. Res.: Solid Earth, 113(B9).

Ulrich, T., A.-A. Gabriel, J. P. Ampuero, and W. Xu, 2019a, Dynamic viability of the $2016 \mathrm{Mw}$ 7.8 Kaikōura earthquake cascade on weak crustal faults, Nat. Commun., 10, no. 1, doi: 10.1038/s41467-019-09125-w.

Ulrich, T., S. Vater, E. H. Madden, J. Behrens, Y. van Dinther, I. van Zelst, E. J. Fielding, C. Liang, and A.-A. Gabriel, 2019b, Coupled, Physics-Based Modeling Reveals Earthquake Displacements are Critical to the 2018 Palu, Sulawesi Tsunami, Pure Appl. Geophys., 176, no. 10, 4069-4109, doi: 10.1007/s00024-019-02290-5.

Ulrich, T., A.-A. Gabriel, and C. Uphoff, 2019c, Are multi-fault rupture and fault roughness compatible? Dynamic rupture modeling of the 2016 Kaikōura, New Zealand, rupture cascade with geometric fault complexity across scales, S51E-0432U presented at the 2019 Fall Meeting, AGU, San Francisco, CA, 9-13 Dec. 


\section{Palgunadi et al., 2020 BSSA Special Issue on Induced Seismicity PREPRINT}

Uphoff, C. and Bader, M., 2016, July. Generating high performance matrix kernels for earthquake simulations with viscoelastic attenuation. In 2016 International Conference on High Performance Computing and Simulation (HPCS) (pp. 908-916). IEEE.

Uphoff, C., S. Rettenberger, M. Bader, E. H. Madden, T. Ulrich, S. Wollherr, and A.-A. Gabriel, 2017, Extreme scale multi-physics simulations of the tsunamigenic 2004 sumatra megathrust earthquake, Proc. Int. Conf. High Perform. Comput. Networking, Storage Anal. - SC ’17, no. November, 1-16, doi: 10.1145/3126908.3126948.

Vavryčuk, V., 2015, Moment tensor decompositions revisited, J. Seismol., 19, no. 1, 231-252, doi: 10.1007/s10950-014-9463-y.

Viesca, R. C., and J. R. Rice, 2012, Nucleation of slip-weakening rupture instability in landslides by localized increase of pore pressure, J. Geophys. Res. Solid Earth, 117, no. 3, doi: 10.1029/2011JB008866.

Wang, Y., G. Ouillon, J. Woessner, D. Sornette, and S. Husen, 2013, Automatic reconstruction of fault networks from seismicity catalogs including location uncertainty, J. Geophys. Res. Solid Earth, 118, no. 11, 5956-5975, doi: 10.1002/2013JB010164.

Wessel, P., W. H. F. Smith, R. Scharroo, J. Luis, and F. Wobbe, 2013, Generic Mapping Tools: Improved Version Released, Eos, Trans. Am. Geophys. Union, 94, no. 45, 409-410, doi: 10.1002/2013EO450001.

Wolf, Sebastian, A.-A. Gabriel, and M. Bader, 2020, Optimisation and Local Time Stepping of an ADER-DG Scheme for Fully Anisotropic Wave Propagation in Complex Geometries, in Proceedings of the 10th International Workshop on Advances in High-Performance 


\section{Palgunadi et al., 2020 BSSA Special Issue on Induced Seismicity PREPRINT}

Computational Earth Sciences: Applications and Frameworks, V. V. Krzhizhanovskaya et al. (Eds.): ICCS 2020, LNCS 12139, pp. 1-14, 2020. doi: https://doi.org/10.1007/978-3$\underline{030-50420-5 \quad 3 \quad 3}$.

Wollherr, S., A.-A. Gabriel, and P. M. Mai, 2019, Landers 1992 "Reloaded": Integrative Dynamic Earthquake Rupture Modeling, J. Geophys. Res. Solid Earth, 124, no. 7, 66666702, doi: 10.1029/2018JB016355.

Wollherr, S., A.-A. Gabriel, and C. Uphoff, 2018, Off-fault plasticity in three-dimensional dynamic rupture simulations using a modal Discontinuous Galerkin method on unstructured meshes: Implementation, verification and application, Geophys. J. Int., 214, no. 3, 15561584, doi: 10.1093/GJI/GGY213.

Woo, J. -U., M. Kim, D. -H. Sheen, T. -S. Kang, J. Rhie, F. Grigoli, W. L. Ellsworth, and D. Giardini, 2019, An In-Depth Seismological Analysis Revealing a Causal Link Between the 2017 M w 5.5 Pohang Earthquake and EGS Project, J. Geophys. Res. Solid Earth, 2019JB018368, doi: 10.1029/2019JB018368.

Yamashita, T., and Y. Umeda, 1994, Earthquake rupture complexity due to dynamic nucleation and interaction of subsidiary faults, Pure Appl. Geophys. PAGEOPH, 143, nos. 1-3, 89116, doi: 10.1007/BF00874325.

Zaliapin, I., and Y. Ben-Zion, 2013, Earthquake clusters in southern California I: Identification and stability, J. Geophys. Res. Solid Earth, 118, no. 6, 2847-2864, doi: 10.1002/jgrb.50179.

van Zelst, I., S. Wollherr, A. -A. Gabriel, E. H. Madden, and Y. Dinther, 2019, Modeling Megathrust Earthquakes Across Scales: One-way Coupling From Geodynamics and 


\title{
Palgunadi et al., 2020 BSSA Special Issue on Induced Seismicity PREPRINT
}

Seismic Cycles to Dynamic Rupture, J. Geophys. Res. Solid Earth, 124, no. 11, 11414 11446, doi: 10.1029/2019JB017539.

Zhan, Z., 2019, Distributed acoustic sensing turns fiber-optic cables into sensitive seismic antennas, Seismol. Res. Lett., 91, no. 1, 1-15, doi: 10.1785/0220190112.

Zhang, Q., and P. M. Shearer, 2016, A new method to identify earthquake swarms applied to seismicity near the San Jacinto Fault, California, Geophys. J. Int., 205, no. 2, 995-1005, doi: $10.1093 /$ gji/ggw073.

Ziegler, M. O., O. Heidbach, A. Zang, P. Martínez-Garzón, and M. Bohnhoff, 2017, Estimation of the differential stress from the stress rotation angle in low permeable rock, Geophys. Res. Lett., 44, no. 13, 6761-6770, doi: 10.1002/2017GL073598.

\author{
FULL AUTHOR'S MAILING LIST: \\ Kadek Hendrawan Palgunadi $\quad$ : kadek.palgunadi@kaust.edu.sa \\ Alice-Agnes Gabriel _ : gabriel@geophysik.uni-muenchen.de \\ Thomas Ulrich : ulrich@geophysik.uni-muenchen.de \\ José Ángel Lopéz-Comino ～: lopezcomino@uni-potsdam.de

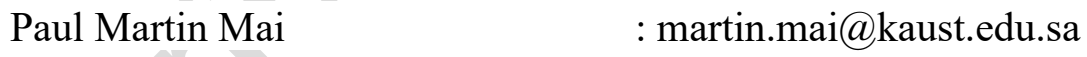

\section{LIST OF TABLE CAPTIONS:}

Table A1. Fault friction parameters assumed in this study

\section{LIST OF FIGURE CAPTIONS:}




\section{Palgunadi et al., 2020 BSSA Special Issue on Induced Seismicity PREPRINT}

Figure 1. Map of the South Korean Peninsula showing the near-regional broadband stations (blue triangles). Solid and dashed lines represent the Yangsan and interpreted geological faults near the Pohang EGS site, respectively. The two inset plots present the location and geometry of the faults of Model 1F (upper panel) and Model 2F (lower panel). The thicker black lines mark the nearsurface edge of the fault planes. Colored dots depict aftershocks locations extracted from Kim et al. (2018). The non-double-couple solution of Grigoli et al. (2018) is also shown.

Figure 2. Fault reconstruction using guided anisotropic location uncertainty distribution (gACLUD). a) Spatiotemporal density plot of the mainshock and aftershocks based on the nearestneighbor distance. b), c) and d) Two fault plane geometry inferred by the g-ACLUD method. The main fault plane (mfp) has a strike of $214^{\circ}$ and dips at $65^{\circ}$, while the secondary fault plane (sfp) has a strike $199^{\circ}$ and dips at $60^{\circ}$. Black dots depict the seismicity used in this study. The black arrow points to the North. The geometry of the faults is shown in views b) view from WNW along the averaged normal vectors of the two fault planes, in c) view from ESE along the averaged backnormal vectors of the two fault planes, and d) view from NNE along the fault strike direction of the main fault plane. The red star denotes the hypocenter of the Pohang earthquake.

Figure 3. 3D rendering of the unstructured tetrahedral computational mesh, and the fault plane with final slip on the two-fault preferred model (Model 2F) of the Pohang earthquake (warm colors,

in $\mathrm{m}$ ), and the radiated seismic wavefield 5 seconds after rupture initiation (cold colors, absolute particle velocity in $\mathrm{m} / \mathrm{s}$ ). Note the strong effect of the high-resolution topography on modulating the seismic wavefield. 


\section{Palgunadi et al., 2020 BSSA Special Issue on Induced Seismicity PREPRINT}

Figure 4. Graphical summary of the outcome of 180 dynamic rupture simulations assuming different combinations of initial relative prestress ratio $\left(R_{0}\right)$, fluid-pressure ratio $(\gamma)$ and direction of $S_{\text {Hmax }}$. The corresponding 180 square frames are filled with color if the combination of parameters is able to trigger self-sustained rupture beyond the nucleation region on any fault. The $S_{\text {Hmax }}$ direction is indicated by the size of the frame, leading to six imbricated frames for each set of prestress and fluid-pressure ratio parameters.

Figure 5. Overview of the simulated earthquake rupture of the preferred model (Model 2F), showing in a) and b) the space-time evolutions of the absolute slip rate (in $\mathrm{m} / \mathrm{s}$ ) across the main (mfp) and secondary fault plane (sfp). a) (left panel) view from WNW along the averaged normal vectors of the two fault planes displaying the main fault rupture. Snapshots every $0.1 \mathrm{~s}$. Two arrows at $t=0.60 \mathrm{~s}$ indicate the successive slip-rates behind the main rupture front. (right panel) view from ESE along the averaged back-normal vectors of the two fault planes highlighting the rupture of a portion of the secondary fault. Snapshots every 0.05 s. b-c) Rupture-time contours at intervals of $0.2 \mathrm{~s}$ across the main (mfp) and secondary fault plane (sfp). The black arrow points to the North.

Figure 6. Moment rate release of a) Model 1F and b) Model 2F and moment tensor representation of the preferred one-fault c) and two-fault d) models.

Figure 7. Distribution of absolute fault slip (in $\mathrm{m}$ ) in a) and b), and rake angles (in degrees) in c) and $\mathrm{d}$ ) for the preferred dynamic rupture scenario (Model 2F) across the main (mfp) and secondary fault plane (sfp). a) and c) view from WNW along the averaged normal vectors of the two fault planes highlighting the main fault rupture. b) and d) view from ESE along the averaged back- 


\section{Palgunadi et al., 2020 BSSA Special Issue on Induced Seismicity PREPRINT}

normal vectors of the two fault planes highlighting the rupture of a portion of the secondary fault. The white star in panel a) marks the considered hypocenter location.

Figure 8. Comparison of synthetic and observed ground motion waveforms. a) Distribution of virtual stations (green triangles) at which synthetic waveforms are compared in b). The beachball is the moment tensor representation of the preferred two fault planes model scenario (Model 2F). Solid and dashed red lines represent the mapped Yangsan fault surface trace and the interpreted fault traces near the Pohang EGS site, respectively. The two rectangles show the location and geometry of the faults used in this study. b) Comparison of synthetic waveforms using one (Model 1F, blue dashed lines) and two fault planes (Model 2F, red solid lines) at the 19 dummy stations located in a). A $0.1-2 \mathrm{~Hz} 4^{\text {th }}$-order Butterworth filter is applied to all traces. All traces are normalized. For each trace, the maximum velocity amplitude (in $\mathrm{m} / \mathrm{s}$ ) of Model $1 \mathrm{~F}$ is indicated within a black square. c) Observed (black) and synthetic (red) waveforms for five regional stations for up-down (UD), east-west (EW) and north-south (NS) components (all located in South Korea, see blue triangles in Figure 1). $t=0 \mathrm{~s}$ denotes the origin time of the Pohang earthquake. A 0.033$0.08 \mathrm{~Hz} 4^{\text {th }}$-order Butterworth filter is applied to all traces. Synthetic regional waveforms are generated from the preferred dynamic rupture scenario Model 2F using Instaseis (Krischer et al., 2017) and 2 s accurate Green's functions based on the PREM anisotropic model.

Figure 9. ((a) and (b)) Modeled co-seismic surface displacements in the InSAR Line-of-sight (LoS) direction (in $\mathrm{m}$ ) generated by a) Model 1F (rectangle) and b) Model 2F (two rectangles), respectively. The dashed red lines represent the traces of the interpreted faults near the EGS site. 
Palgunadi et al., 2020 BSSA Special Issue on Induced Seismicity PREPRINT

\section{LIST OF TABLES:}

Table A1. Fault friction parameters assumed in this study

\begin{tabular}{|l|c|l|}
\hline \multicolumn{1}{|c|}{ Parameter } & Symbol & \multicolumn{1}{|c|}{ Value } \\
\hline Direct effect parameter & $a$ & $0.01-0.02 \mathrm{z} \leq 3.3 \mathrm{~km}$ and \\
& & $0.01 \mathrm{z}>3.3 \mathrm{~km}$ \\
\hline Evolution effect parameter & $b$ & 0.014 \\
\hline Reference slip velocity & $V_{0}$ & $10^{-6} \mathrm{~m} / \mathrm{s}$ \\
\hline Steady-state friction coefficient at $V_{0}$ & $f_{0}$ & 0.6 \\
\hline State-evolution distance & $L$ & $0.2 \mathrm{~m}$ \\
\hline Weakening slip velocity & $V_{W}$ & $0.1-1.0 \mathrm{z} \leq 3.3 \mathrm{~km}$ and $0.1 \mathrm{z}$ \\
& & $>3.3 \mathrm{~km}$ \\
\hline Fully weakened friction coefficient & $f_{W}$ & 0.1 \\
\hline Initial slip rate & $V_{i n i}$ & $10^{-16} \mathrm{~m} / \mathrm{s}$ \\
\hline
\end{tabular}




\section{Palgunadi et al., 2020 BSSA Special Issue on Induced Seismicity PREPRINT}

\section{LIST OF FIGURES:}

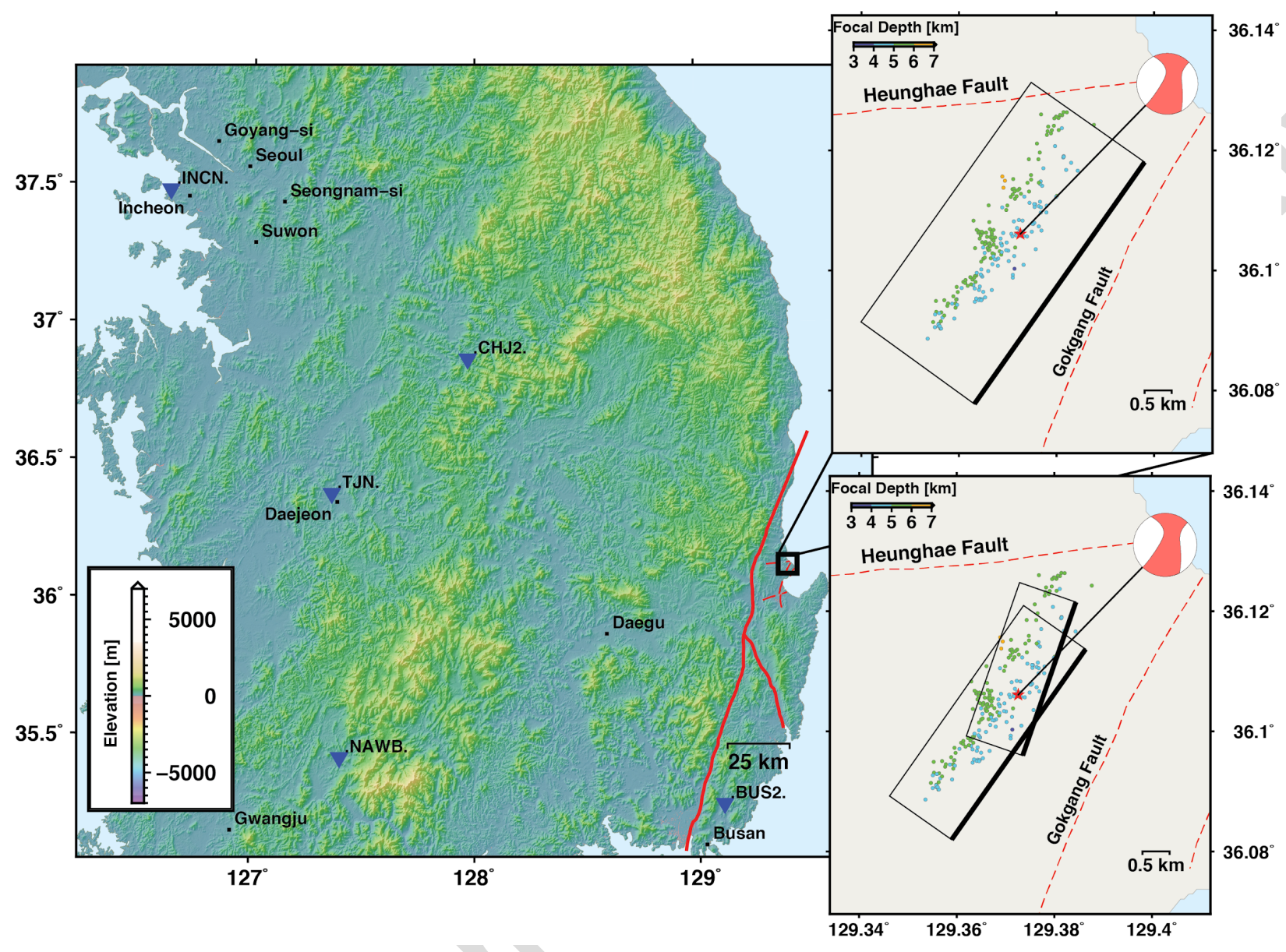

Figure 1. Map of the South Korean Peninsula showing the near-regional broadband stations (blue triangles). Solid and dashed lines represent the Yangsan and interpreted geological faults near the Pohang EGS site, respectively. The two inset plots present the location and geometry of the faults of Model 1F (upper panel) and Model 2F (lower panel). The thicker black lines mark the nearsurface edge of the fault planes. Colored dots depict aftershocks locations extracted from Kim et al. (2018). The non-double-couple solution of Grigoli et al. (2018) is also shown. 
Palgunadi et al., 2020 BSSA Special Issue on Induced Seismicity PREPRINT

a)

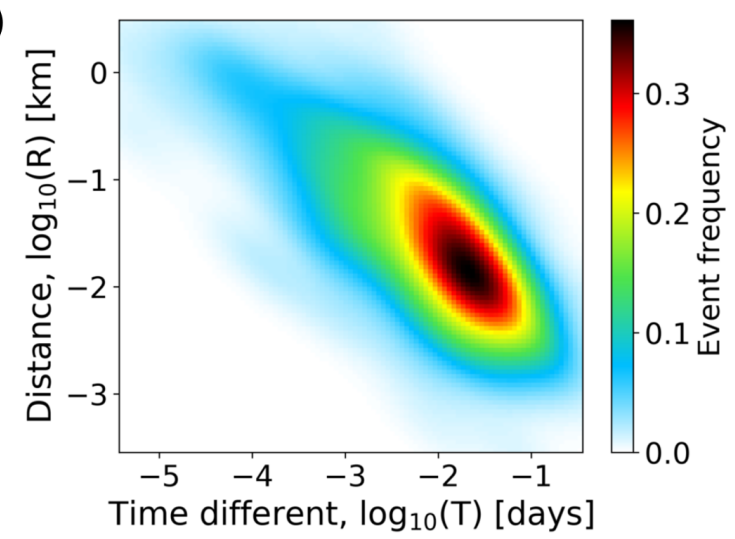

c)

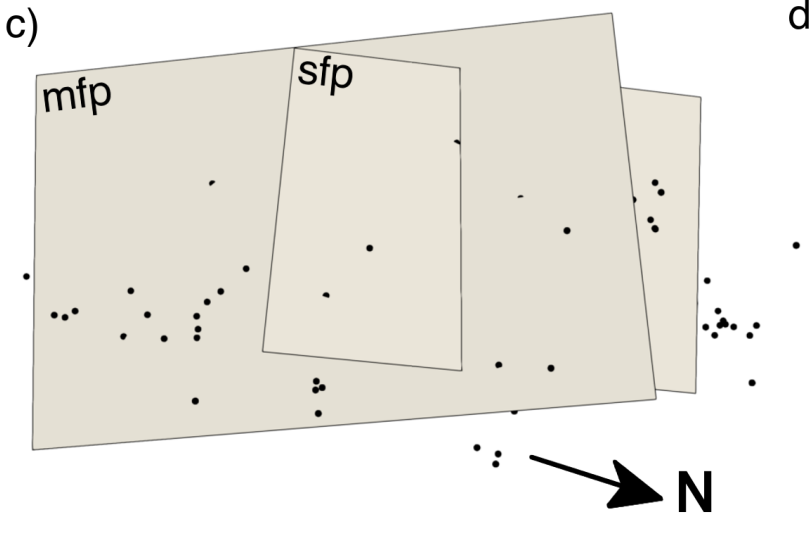

b)

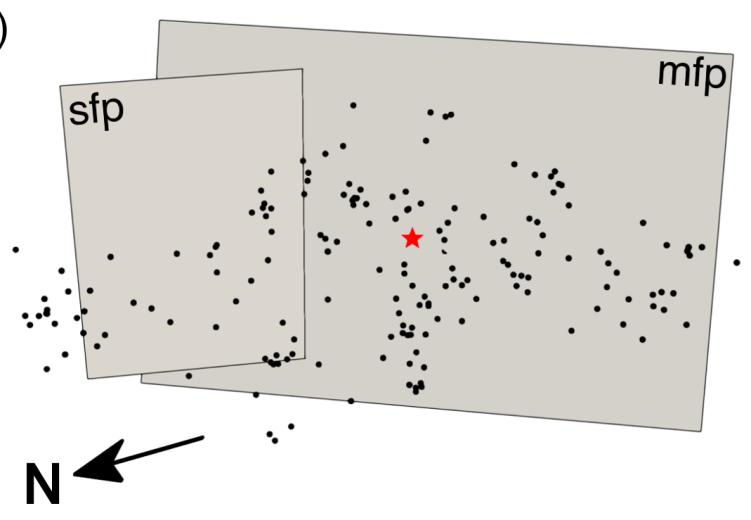

d)

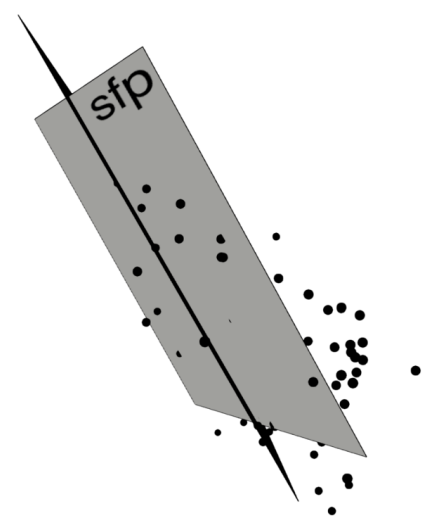

Figure 2. Fault reconstruction using guided anisotropic location uncertainty distribution (gACLUD). a) Spatiotemporal density plot of the mainshock and aftershocks based on the nearestneighbor distance. b), c) and d) Two fault plane geometry inferred by the g-ACLUD method. The main fault plane (mfp) has a strike of $214^{\circ}$ and dips at $65^{\circ}$, while the secondary fault plane (sfp) has a strike $199^{\circ}$ and dips at $60^{\circ}$. Black dots depict the seismicity used in this study. The black arrow points to the North. The geometry of the faults is shown in views b) view from WNW along the averaged normal vectors of the two fault planes, in c) view from ESE along the averaged backnormal vectors of the two fault planes, and d) view from NNE along the fault strike direction of the main fault plane. The red star denotes the hypocenter of the Pohang earthquake. 


\section{Palgunadi et al., 2020 BSSA Special Issue on Induced Seismicity PREPRINT}

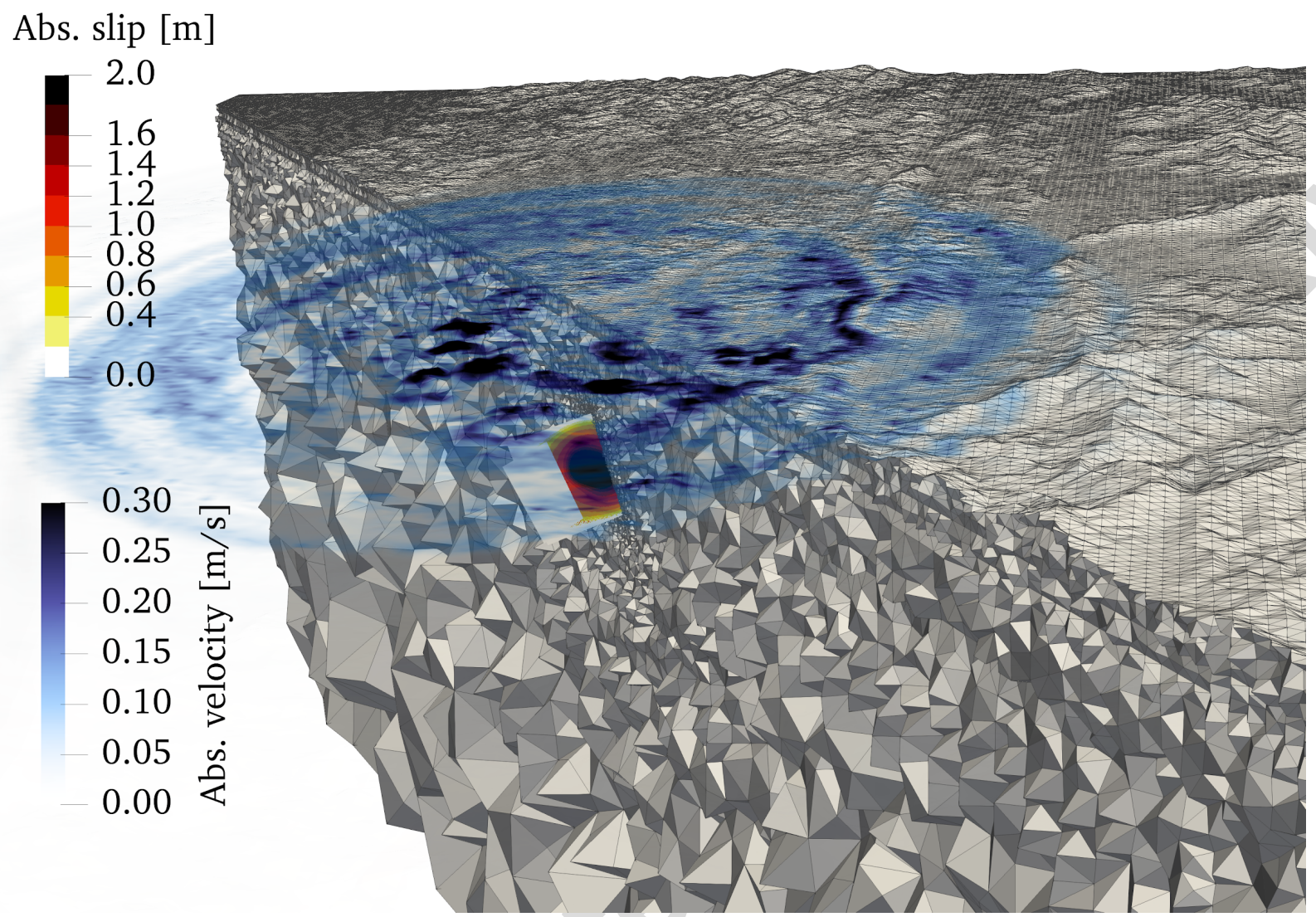

Figure 3. 3D rendering of the unstructured tetrahedral computational mesh, and the fault plane with final slip on the two-fault preferred model (Model 2F) of the Pohang earthquake (warm colors, in $\mathrm{m}$ ), and the radiated seismic wavefield 5 seconds after rupture initiation (cold colors, absolute particle velocity in $\mathrm{m} / \mathrm{s}$ ). Note the strong effect of the high-resolution topography on modulating the seismic wavefield. 
Palgunadi et al., 2020 BSSA Special Issue on Induced Seismicity PREPRINT

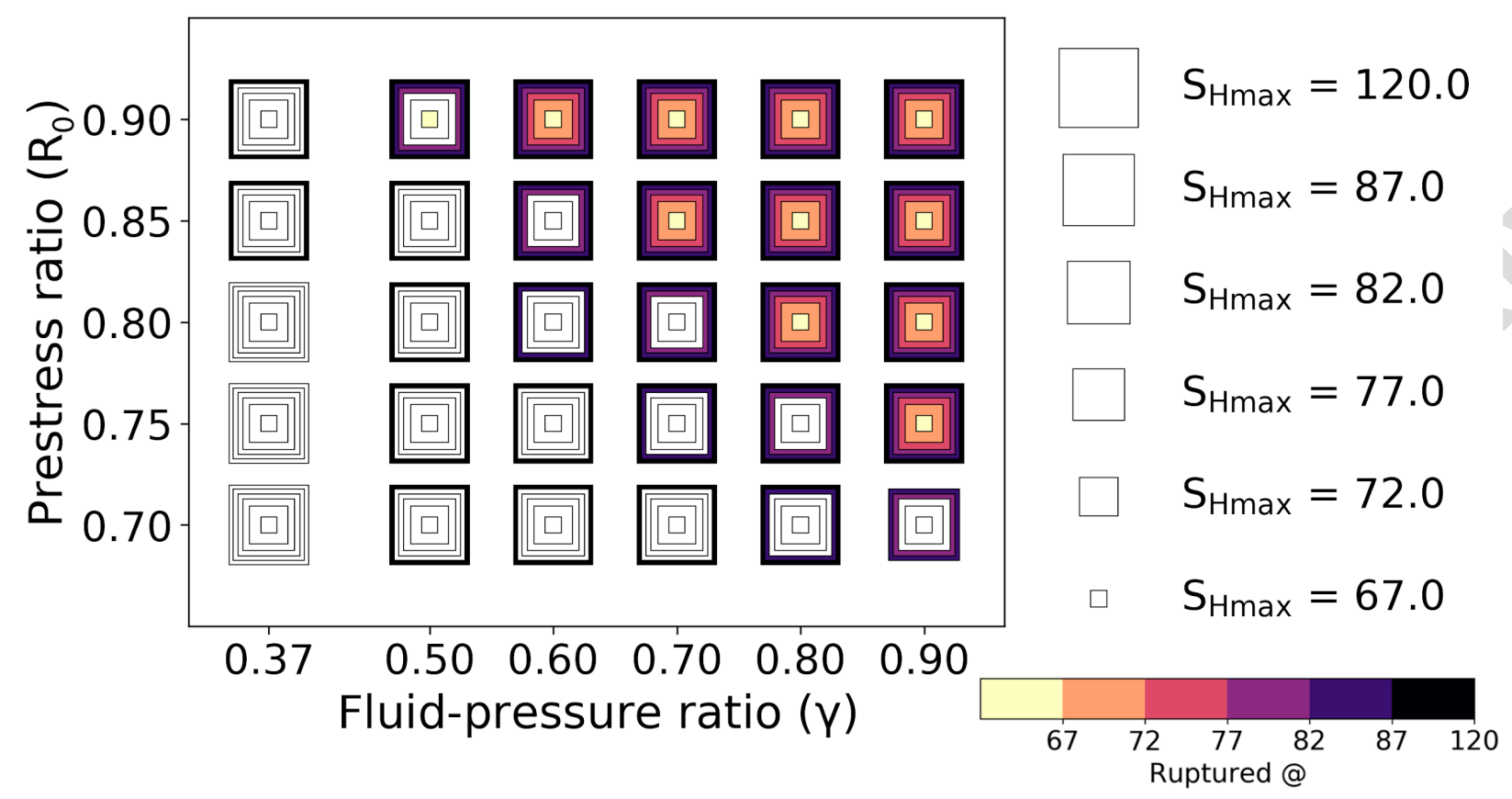

Figure 4. Graphical summary of the outcome of 180 dynamic rupture simulations assuming different combinations of initial relative prestress ratio $\left(R_{0}\right)$, fluid-pressure ratio $(\gamma)$ and direction of $S_{\text {Hmax }}$. The corresponding 180 square frames are filled with color if the combination of parameters is able to trigger self-sustained rupture beyond the nucleation region on any fault. The $S_{\text {Hmax }}$ direction is indicated by the size of the frame, leading to six imbricated frames for each set of prestress and fluid-pressure ratio parameters. 
Palgunadi et al., 2020 BSSA Special Issue on Induced Seismicity PREPRINT

Slip rate $[\mathrm{m} / \mathrm{s}]$

$\begin{array}{lllllllll}0.0 & 1.0 & 2.0 & 3.0 & 4.0 & 5.0 & 6.0 & 7.0 & 8.0\end{array}$

a)
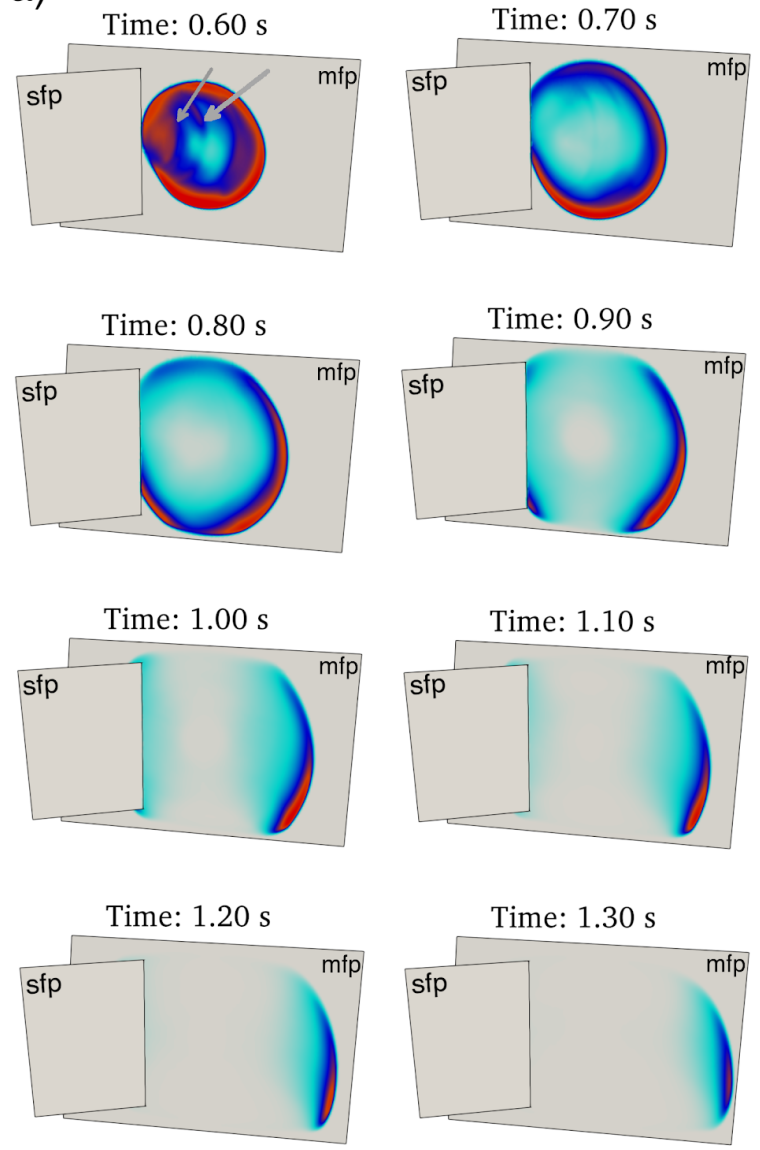

Time: $1.10 \mathrm{~s}$

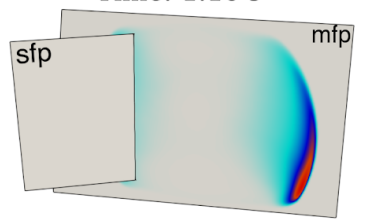

Time: $1.30 \mathrm{~s}$

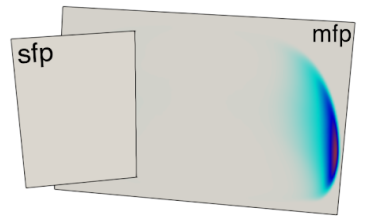

b)

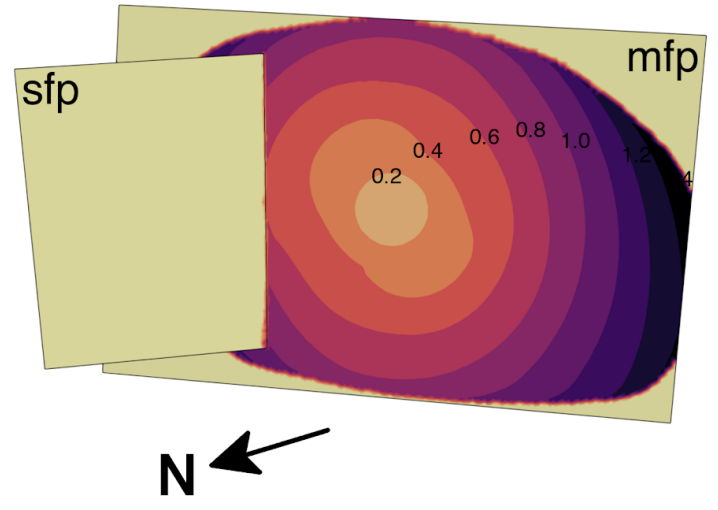

Time: $0.40 \mathrm{~s}$

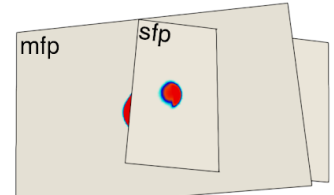

Time: $0.50 \mathrm{~s}$

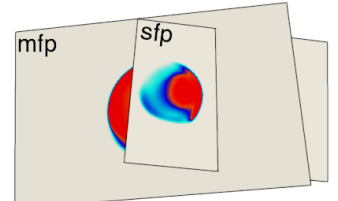

Time: $0.60 \mathrm{~s}$

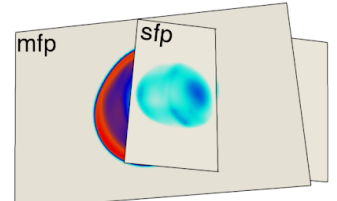

Time: $0.70 \mathrm{~s}$
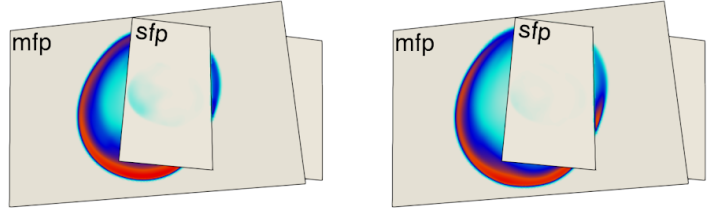

c)

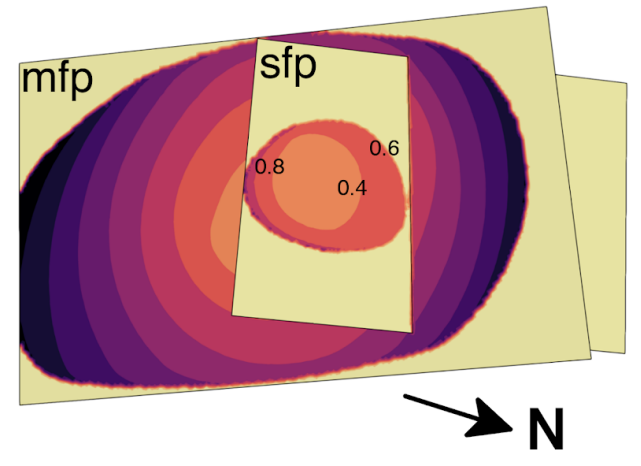




\section{Palgunadi et al., 2020 BSSA Special Issue on Induced Seismicity PREPRINT}

Figure 5. Overview of the simulated earthquake rupture of the preferred model (Model 2F), showing in a) and b) the space-time evolutions of the absolute slip rate (in $\mathrm{m} / \mathrm{s}$ ) across the main (mfp) and secondary fault plane (sfp). a) (left panel) view from WNW along the averaged normal vectors of the two fault planes displaying the main fault rupture. Snapshots every $0.1 \mathrm{~s}$. Two arrows at $t=0.60 \mathrm{~s}$ indicate the successive slip-rates behind the main rupture front. (right panel) view from ESE along the averaged back-normal vectors of the two fault planes highlighting the rupture of a portion of the secondary fault. Snapshots every $0.05 \mathrm{s.} \mathrm{b}-\mathrm{c})$ Rupture-time contours at intervals of $0.2 \mathrm{~s}$ across the main (mfp) and secondary fault plane (sfp). The black arrow points to the North. 
Palgunadi et al., 2020 BSSA Special Issue on Induced Seismicity PREPRINT

a)

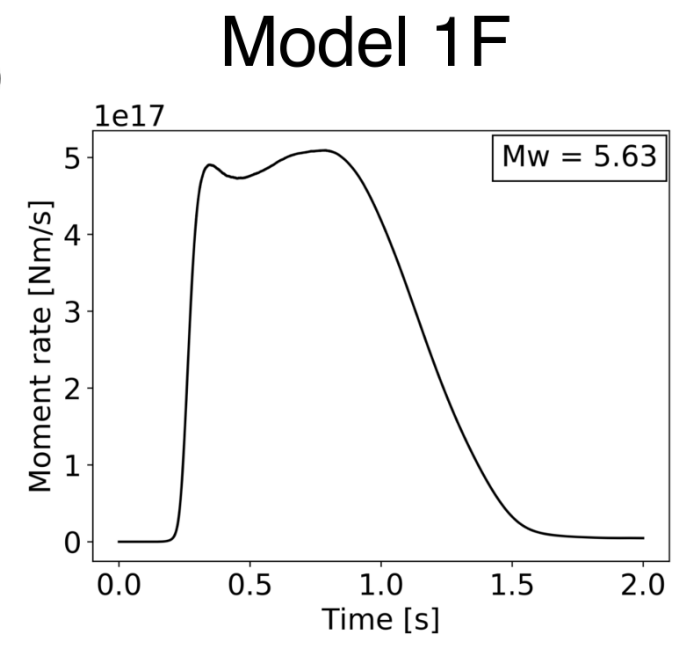

c) Model 1F

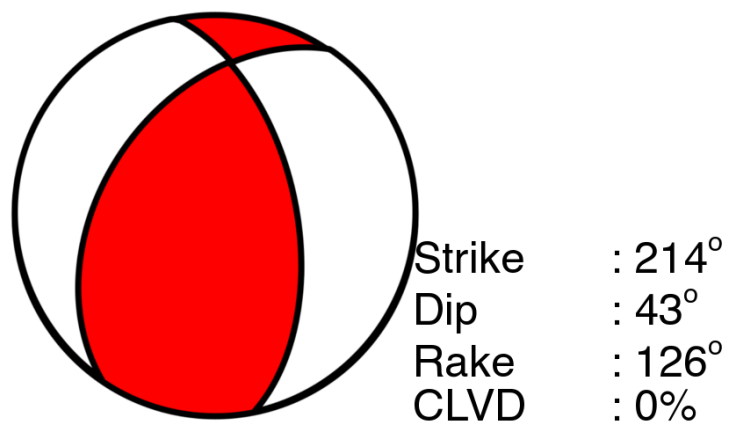

b) Model 2F

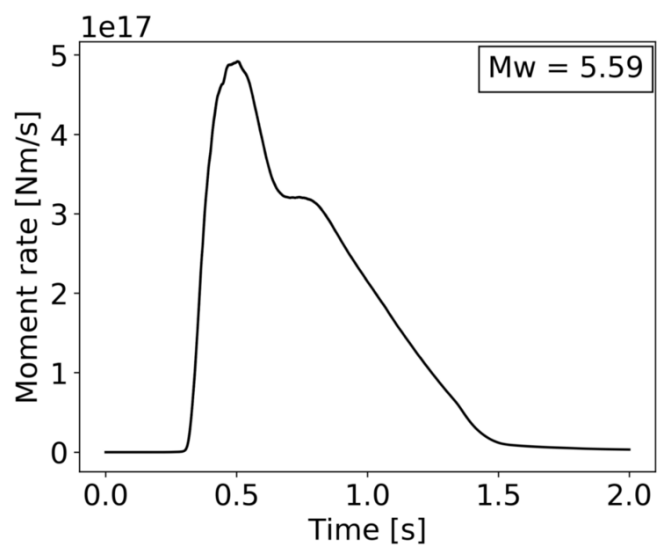

d) Model 2F

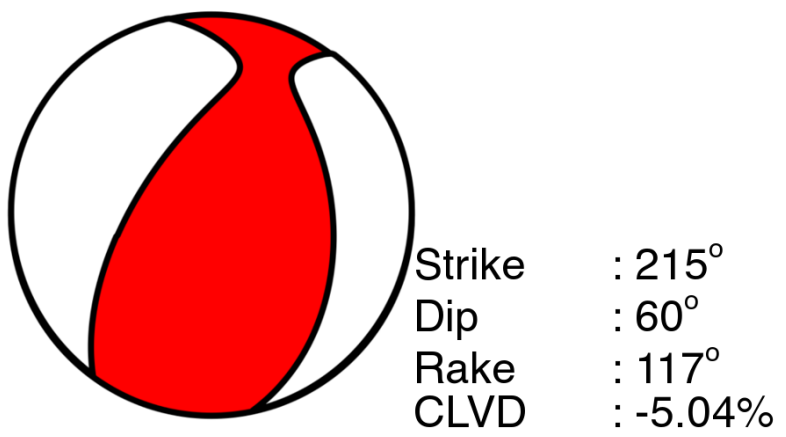

Figure 6. Moment rate release of a) Model $1 \mathrm{~F}$ and b) Model 2F and moment tensor representation of the preferred one-fault c) and two-fault d) models. 


\section{Palgunadi et al., 2020 BSSA Special Issue on Induced Seismicity}

PREPRINT

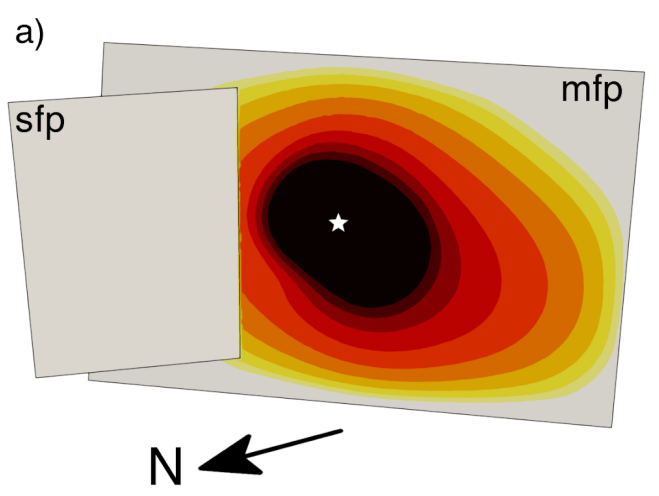

b)
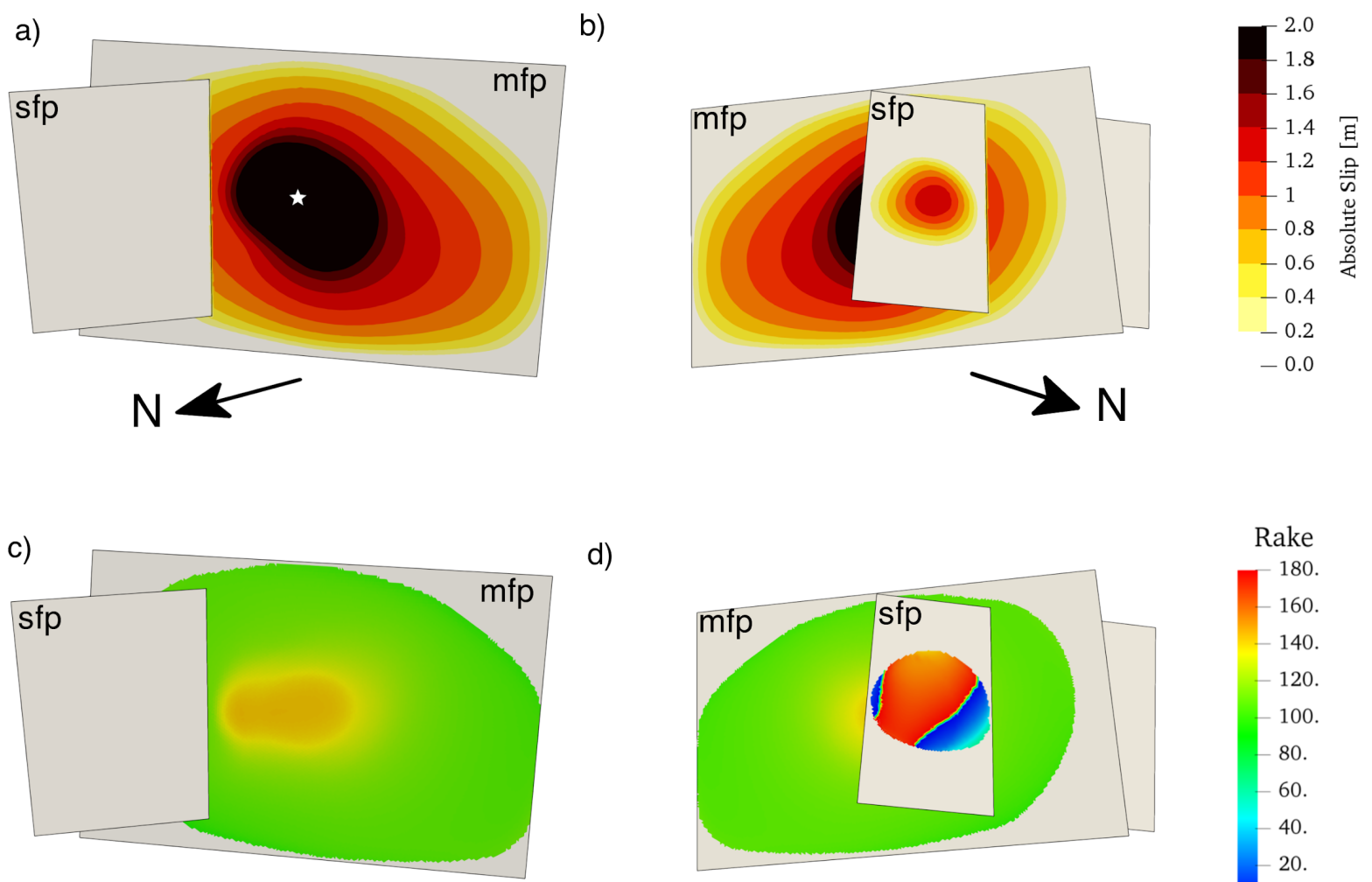

d)

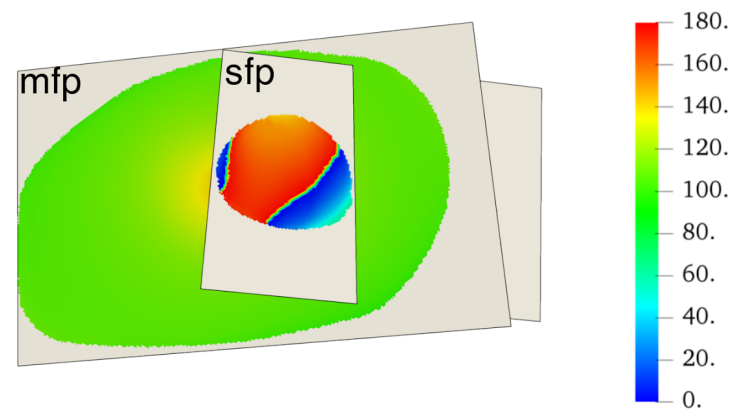

Figure 7. Distribution of absolute fault slip (in m) in a) and b), and rake angles (in degrees) in c) and d) for the preferred dynamic rupture scenario (Model 2F) across the main (mfp) and secondary fault plane (sfp). a) and c) view from WNW along the averaged normal vectors of the two fault planes highlighting the main fault rupture. b) and d) view from ESE along the averaged backnormal vectors of the two fault planes highlighting the rupture of a portion of the secondary fault. The white star in panel a) marks the considered hypocenter location. 


\section{Palgunadi et al., 2020 BSSA Special Issue on Induced Seismicity PREPRINT}
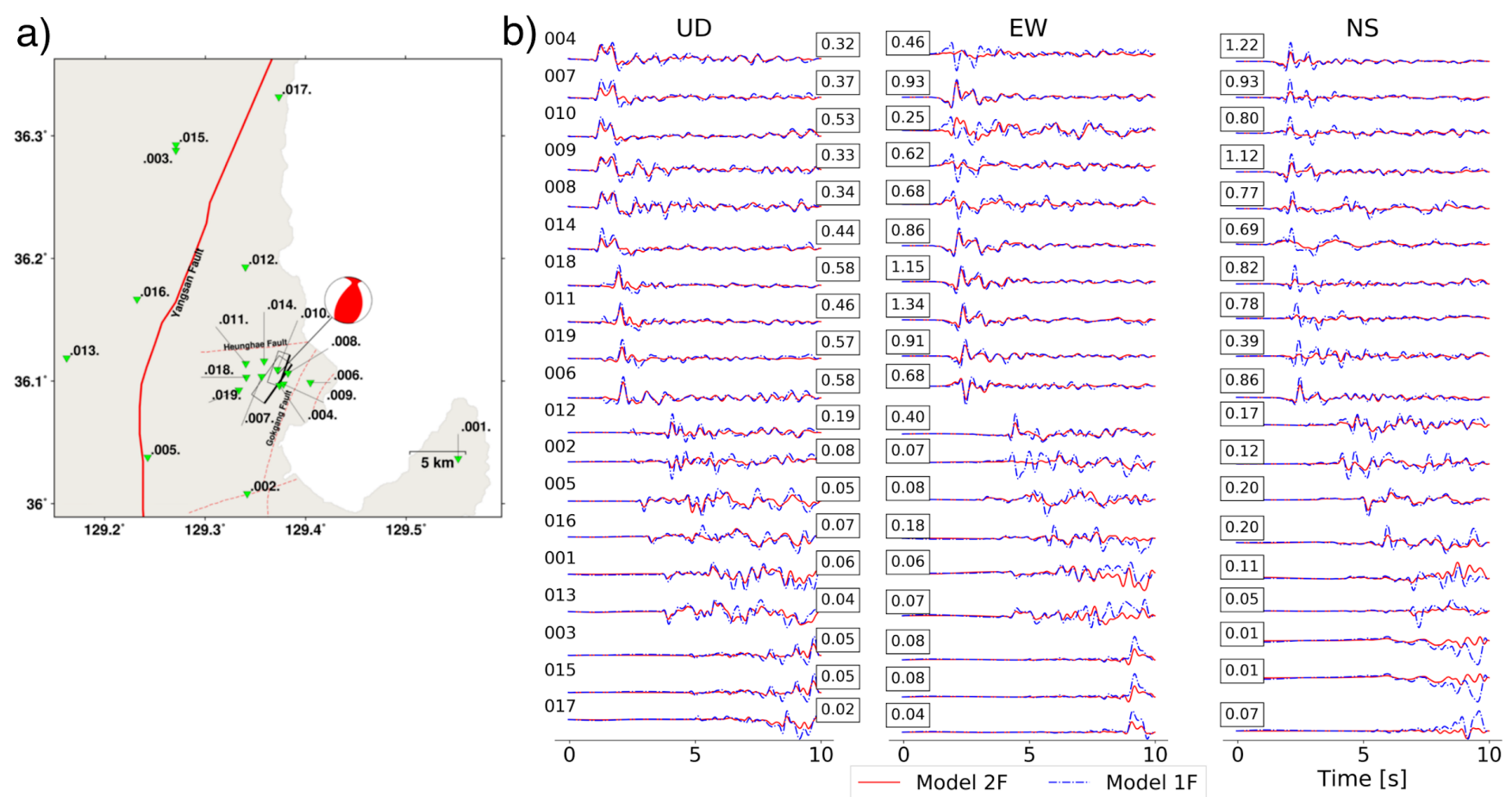

c)

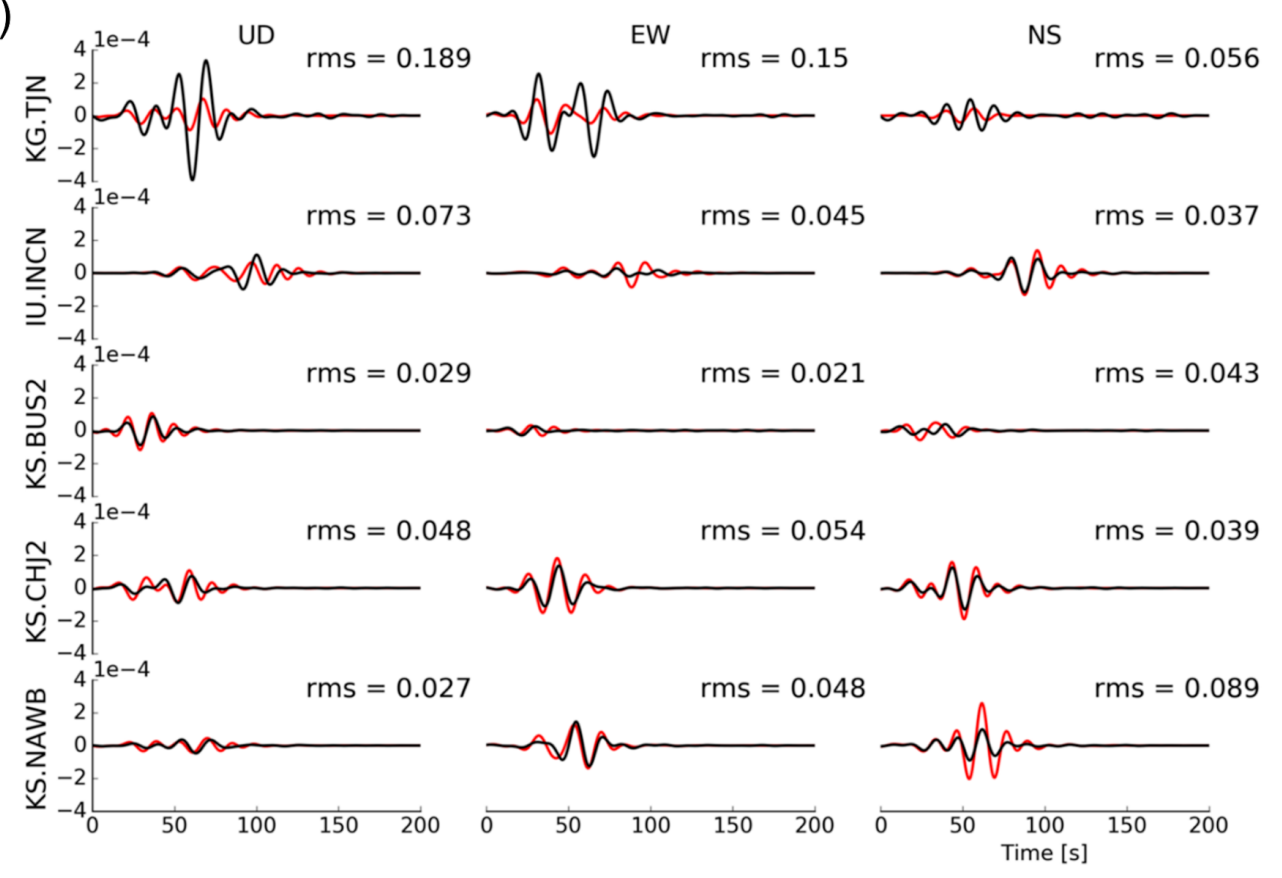

Figure 8. Comparison of synthetic and observed ground motion waveforms. a) Distribution of virtual stations (green triangles) at which synthetic waveforms are compared in b). The beachball is the moment tensor representation of the preferred two fault planes model scenario (Model 2F). Solid and dashed red lines represent the mapped Yangsan fault surface trace and the interpreted 


\section{Palgunadi et al., 2020 BSSA Special Issue on Induced Seismicity PREPRINT}

fault traces near the Pohang EGS site, respectively. The two rectangles show the location and geometry of the faults used in this study. b) Comparison of synthetic waveforms using one (Model $1 \mathrm{~F}$, blue dashed lines) and two fault planes (Model 2F, red solid lines) at the 19 dummy stations located in a). A $0.1-2 \mathrm{~Hz} 4^{\text {th }}$-order Butterworth filter is applied to all traces. All traces are normalized. For each trace, the maximum velocity amplitude (in $\mathrm{m} / \mathrm{s}$ ) of Model $1 \mathrm{~F}$ is indicated within a black square. c) Observed (black) and synthetic (red) waveforms for five regional stations for up-down (UD), east-west (EW) and north-south (NS) components (all located in South Korea, see blue triangles in Figure 1). $t=0 \mathrm{~s}$ denotes the origin time of the Pohang earthquake. A 0.033$0.08 \mathrm{~Hz} 4^{\text {th }}$ - order Butterworth filter is applied to all traces. Synthetic regional waveforms are generated from the preferred dynamic rupture scenario Model 2F using Instaseis (Krischer et al., 2017) and $2 \mathrm{~s}$ accurate Green's functions based on the PREM anisotropic model. 
Palgunadi et al., 2020 BSSA Special Issue on Induced Seismicity PREPRINT
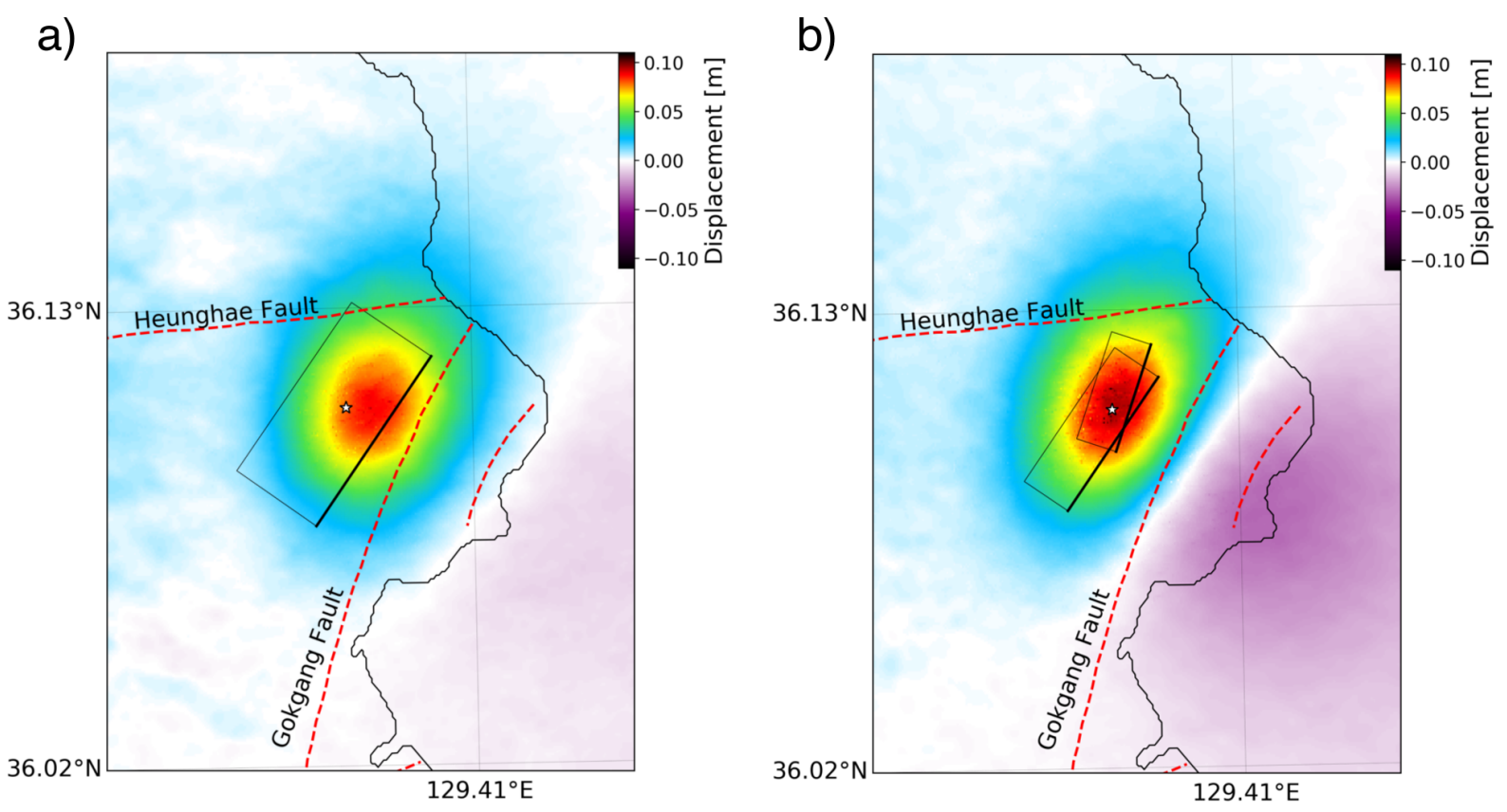

Figure 9. ((a) and (b)) Modeled co-seismic surface displacements in the InSAR Line-of-sight (LoS) direction (in $\mathrm{m}$ ) generated by a) Model 1F (rectangle) and b) Model 2F; (two rectangles), respectively. The dashed red lines represent the traces of the interpreted faults near the EGS site.

\section{APPENDIX}

\section{Friction parameters}

To parameterize the frictional behavior, we use laboratory-based rapid velocity weakening friction law proposed by the community benchmark problem TPV104 Southern California Earthquake Center (SCEC-benchmark) (Harris et al., 2018). The friction law is adapted from - the formulation introduced by Dunham et al. (2011a). The governing equations in our notation are described in Ulrich et al. (2019a), the implementation in SeisSol (see Data and Resources) is described and verified in Pelties et al. (2014). Figure S1b shows the depth-dependent direct effect $a$ and weakening slip velocity $V_{W}$. The evolution effect parameter $b$ is set constant. We apply a velocity 


\section{Palgunadi et al., 2020 BSSA Special Issue on Induced Seismicity PREPRINT}

strengthening zone at the top $200 \mathrm{~m}$ of all faults to smoothly stop rupture. Within this zone, values for $a$ and $V_{W}$ increase linearly ranging from 0.01 and $0.1 \mathrm{~m} / \mathrm{s}$ below depth of $3.3 \mathrm{~km}$ to 0.02 and $1.0 \mathrm{~m} / \mathrm{s}$ to the surface, respectively. Table A1 lists all friction parameters used in this study.

Table A1. Fault friction parameters assumed in this study

\begin{tabular}{|c|c|c|}
\hline Parameter & Symbol & Value \\
\hline Direct effect parameter & $a$ & $\begin{array}{l}0.01-0.02 \mathrm{z} \leq 3.3 \mathrm{~km} \text { and } \\
0.01 \mathrm{z}>3.3 \mathrm{~km}\end{array}$ \\
\hline Evolution effect parameter & $b$ & 0.014 \\
\hline Reference slip velocity & $V_{0}$ & $10^{-6} \mathrm{~m} / \mathrm{s}$ \\
\hline Steady-state friction coefficient at $V_{0}$ & $f_{0}$ & 0.6 \\
\hline State-evolution distance & $L$ & $0.2 \mathrm{~m}$ \\
\hline Weakening slip velocity & $V_{W}$ & $\begin{array}{l}0.1-1.0 \mathrm{z} \leq 3.3 \mathrm{~km} \text { and } 0.1 \mathrm{z} \\
>3.3 \mathrm{~km}\end{array}$ \\
\hline Fully weakened friction coefficient & $f_{W}$ & 0.1 \\
\hline Initial slip rate & $V_{\text {ini }}$ & $10^{-16} \mathrm{~m} / \mathrm{s}$ \\
\hline
\end{tabular}

\section{Nucleation procedure}




\section{Palgunadi et al., 2020 BSSA Special Issue on Induced Seismicity PREPRINT}

To nucleate the earthquake, we apply a time-dependent overstress centered at the hypocenter location, that is at longitude and latitude of $129.37^{\circ}$ and $36.11^{\circ}$, respectively, and at a depth of 4.27 $\mathrm{km}$. The time-dependent overstressed nucleation area $R_{n u c}(t)$ is determined by increasing the initial relative prestress ratio $R_{0}$ as:

$$
R_{n u c}(t)=R_{0}+\Omega(r) \times S(t)
$$

where $\Omega(r)$ is a Gaussian-step function, $r$ is the radius from the hypocenter, and $S(t)$ denotes the smoothed step function. The Gaussian-step function is defined as:

$$
\Omega(r)=\xi \exp \left(\frac{r^{2}}{r^{2}-r_{c}^{2}}\right) \text { for } \mathrm{r}<r_{c} ; \quad \Omega(r)=0 \quad \text { otherwise }
$$

where $\xi$ is the overstressed initial relative prestress ratio and $r_{c}=500 \mathrm{~m}$ is the radius of the nucleation patch. We only overstress the main fault plane; In the nucleation region, we set $\xi$ to 2 , and apply an overstress characterized by $S_{H \max }=77^{\circ}$ and $v=0.1$. These values are set by trialand-error to allow rupture to propagate spontaneously with the least magnitude of overstress and to limit fault slip inside the nucleation patch. The orientation of $S_{H \max }$ is also in accordance with Korean Government Commission, 2019 and Ellsworth et al. (2019) which suggest optimally oriented stress orientation and critically stressed inside the nucleation zone. The smoothed step function is formulated as:

$$
S(t)=\exp \left(\frac{(t-T)^{2}}{t \times(t-2 \times T)}\right) \quad \text { for } 0<t<T ; S(t)=1 \text { for } t \geq T
$$




\section{Palgunadi et al., 2020 BSSA Special Issue on Induced Seismicity PREPRINT}

where $T=0.4 \mathrm{~s}$ is the nucleation time.

\section{Numerical method}

We use the open-source software SeisSol (Dumbser and Käser, 2006; Pelties et al., 2014; Uphoff et al., 2017; Wollherr et al., 2018) (see Data and Resources), which couples seismic wave propagation in complex media and frictional fault failure. SeisSol uses an Arbitrary high-order DERivative-Discontinuous Galerkin (ADER-DG) approach which achieves high-order accuracy in space and time (Käser and Dumbser, 2006). SeisSol uses flexible non-uniform unstructured tetrahedral mesh, which allows accounting for complex geometric features such as 3D fault networks or high-resolution topography across a large range of scales: from small-scale fault roughness, large-scale fault structures to fault-to-fault interaction. Dynamic rupture simulations are sensitive to geometrically complexity of faults (Dunham et al., 2011b; Shi and Day, 2013; Uphoff et al., 2017; Wollherr et al., 2018, 2019; Ulrich et al., 2019a, 2019b).

A high resolution and accurate simulation are essential to resolve the detailed processes of rupture propagation of the intersected fault geometry. We motivate the presented deterministic parameter study with the computational feasibility of many such simulations. While the feasibility of dynamic rupture inversion and statistical learning approaches has been demonstrated (e.g. Peyrat et al. 2001; Bauer et al., 2018, Happ et al. 2019, Gallovič et al. 2019a, Gallovič et al. 2019b), these are restricted by near-field data availability and the computational cost of each forward dynamic rupture model.

SeisSol is verified in a wide range of benchmark problems, including dipping faults, branched and curved faults, on-fault heterogeneity, and laboratory-based friction laws (de la 


\section{Palgunadi et al., 2020 BSSA Special Issue on Induced Seismicity PREPRINT}

Puente et al., 2009; Pelties et al., 2012; Pelties et al., 2014; Wollherr et al., 2018,) in line with the SCEC-Benchmark Dynamic Rupture code verification exercises (Harris et al., 2011; Harris et al., 2018) as well as against analytical reference solutions for seismic wave propagation (e.g., Uphoff and Bader, 2016; Wolf et al., 2020). Fast time to solution is achieved using end-to-end optimization (Breuer et al., 2014; Heinecke et al., 2014; Rettenberger et al., 2016), including an efficient local time-stepping algorithm (Breuer et al., 2016, Uphoff et al., 2017). This efficient algorithm on highperformance computing architecture provides up to ten-fold speed up (Uphoff et al., 2017).

SeisSol allows accounting for off-fault yielding. Inelastic energy dissipation influences rupture dynamics such as rupture speed and rupture style (e.g., Gabriel et al., 2013). Off-fault plasticity is incorporated using the off-line code generator to compute matrix operations in an efficient way (Wollherr et al., 2018). SeisSol also supports visco-elastic rheologies, using an offline code generator similar to that of off-fault plasticity. In this study, we use a spatiotemporal discretization of polynomial degree $p=4(05)$ for all simulations.

\section{Mesh generation}

The simulation domain and fault plane geometry model are created using third-party software GoCad (Emerson paradigm holding, 2018) in a Cartesian coordinate system. We discretize the unstructured tetrahedral mesh using the meshing software Simmodeler (Simmetrix Inc., 2017). The mesh element edge length is $50 \mathrm{~m}$ close to the fault plane and $200 \mathrm{~m}$ at the surface topography, yielding a 4 million volume cell mesh. The mesh size on the fault plane is examined prior to the simulation by calculating the cohesive zone (or process zone) to ensure convergence. Wollherr et al. $(2018,2019)$ provide a way to resolve the cohesive zone for the case of SeisSol. To save the computational costs and at the same time avoid reflection from the domain boundary, we gradually 


\section{Palgunadi et al., 2020 BSSA Special Issue on Induced Seismicity PREPRINT}

increase the edge length size of the tetrahedral element by a factor of $6 \%$ away from the fault plane and surface topography. Figure 3 depicts the unstructured tetrahedral mesh used in this study, overlain by a snapshot of the absolute velocity field at simulation time $t=5 \mathrm{~s}$, for our preferred dynamic rupture model (Model 2F), highlighting the effect of the topography on the near-field ground motions.

The locally refined mesh and high-order spatiotemporal discretization allow capturing the high-frequency content of the waveforms with high accuracy (little numerical dispersion), especially in the near-fault region. We estimate the maximum resolved frequency is up to $4 \mathrm{~Hz}$ within $7 \mathrm{~km}$ distance from the fault zone, and around $1 \mathrm{~Hz}$ at $30 \mathrm{~km}$ distance from the fault. Simulating 5 s typically requires 15 minutes (average run-time) on Intel Haswell cores with 128 nodes using supercomputer Cray XC40 Shaheen-II, King Abdullah University of Science and Technology, Saudi Arabia. 
Palgunadi et al., 2020 BSSA Special Issue on Induced Seismicity PREPRINT

\author{
Supplemental Material for
}

\title{
Dynamic fault interaction during a fluid-injection induced
}

\section{earthquake: The 2017 Mw 5.5 Pohang event}

\author{
K. H. Palgunadi, A.-A Gabriel, T. Ulrich, J. A. Lopéz-Comino, P. M. Mai
}

This supplement includes additional figures, a table, a zipped file, and videos supporting the outcome of the study. The figures consist of depth-dependent 1D subsurface material and friction parameters, part of static modeling, peak slip rate distribution, off-fault plastic deformation, synthetic surface displacements, and shake-map. The table contains the rake of initial traction of two-fault planes geometry using static modeling. The zipped file consists of all parameters used for the preferred two-fault planes scenario. The videos show snapshots of the slip rate in two perspective views (presenting the main and secondary fault plane) of the preferred twofault planes scenario.

\section{LIST OF SUPPLEMENTAL TABLE CAPTIONS:}

Table S1. Rake of initial shear traction on the faults of Model 2F

\section{LIST OF SUPPLEMENTAL FIGURE CAPTIONS:}

Figure S1. Vertical profiles of a) the 1-D model of seismic wave speeds by Woo et al. (2019) and by Korean Government Commission (2019). Panel b) displays the depth-dependent parameters of the velocity weakening rate-and-state friction law. 


\section{Palgunadi et al., 2020 BSSA Special Issue on Induced Seismicity PREPRINT}

Figure S2. Rake of initial (at $t=0$ ) shear traction for exemplary orientations of maximum horizontal stress $S_{H \max }$ (see also Table S1). Thrust-faulting is favored for $S_{H \max }=120^{\circ}$. Note that $S_{\text {Hax }}=77^{\circ}$ corresponds to the findings of Ellsworth et al. (2019).

Figure S3. Peak slip rate of Model 2F. The maximum peak slip rate (yellow color, saturated at 10 $\mathrm{m} / \mathrm{s}$ ) outside the nucleation zone is $15 \mathrm{~m} / \mathrm{s}$. View from a) WNW along the averaged normal vectors of the two fault planes and b) ESE along the averaged back-normal vectors of the two fault planes.

Figure S4. Asymmetric off-fault plastic deformation for Model 1F ( $a$ and b) and Model 2F (c and d). a) and c) view from WNW along the averaged normal vectors of the two fault planes b) and d) view from ESE along the averaged back-normal vectors of the two fault planes. The accumulated volumetric plastic strain is mapped into the scalar quantity $\eta$ denoted by the purple colorbar (purple color, saturated at $10^{-7}$ ). Following Wollherr et al. (2019), the characteristics of fault zone width can be qualitatively compared to the spatial distribution of the modeled co-seismic plastic deformation. We infer high co-seismic damage close to the fault intersection, and an increasing fault zone width near the surface, yet, off-fault damage not reaching the free surface.

Figure S5. Modeled surface displacements of Model 2F. a) Modeled co-seismic surface displacements using only the main fault plane of Model 2F. The rectangle illustrates the fault plane. b) The difference between the modeled co-seismic displacement of Model 2F and Model $2 \mathrm{~F}$ using only the main plane. The dashed red lines represent the traces of the interpreted faults near the EGS site. The white star represents the epicenter of the Pohang earthquake. 


\section{Palgunadi et al., 2020 BSSA Special Issue on Induced Seismicity PREPRINT}

Figure S6. Waveform comparison between two synthetics generated by point source modeling of our preferred Model 2F and the moment tensor solution of Grigoli et al. (2018). $t=0 \mathrm{~s}$ denotes the origin time of the Pohang earthquake. A $0.033-0.08 \mathrm{~Hz} 4^{\text {th }}$ - order Butterworth filter is applied to all traces.

Figure S7. Peak ground velocity shake-map (in m/s, based on GMRotD50 (Boore et al., 2006)) for the preferred Model 2F (color-contoured $0.2 \mathrm{~m} / \mathrm{s}$ increments). The white star denotes the epicenter of the Pohang earthquake.

\section{LIST OF SUPPLEMENTAL FILES:}

Video S1. Slip rate of Model 2F. The video also can be accessed in https://drive.google.com/open?id=1nm3HZ YOD-j8t YatTFfs9prVKplEExj

Parameters.zip (this file contains all parameters used for the preferred Model 2F. The input files are available in this link: https://drive.google.com/open?id=1nm3HZ_YODj8t_YatTFfs9prVKplEExj) 
Palgunadi et al., 2020 BSSA Special Issue on Induced Seismicity PREPRINT

\section{LIST OF SUPPLEMENTAL TABLES:}

Table S1. Rake of initial shear traction on the faults of Model 2F

\begin{tabular}{|c|c|c|}
\hline$S_{\text {Hmax }}$ & Main fault rake $\left(^{\circ}\right)$ & Secondary fault rake $\left(^{\circ}\right)$ \\
\hline 52 & 0 & 12 \\
\hline 57 & 3 & 16 \\
\hline 62 & 7 & 20 \\
\hline 67 & 11 & 24 \\
\hline 72 & 15 & 29 \\
\hline 77 & 19 & 35 \\
\hline 82 & 23 & 41 \\
\hline 87 & 28 & 48 \\
\hline 92 & 34 & 57 \\
\hline 97 & 40 & 66 \\
\hline 102 & 47 & 77 \\
\hline 107 & 55 & 88 \\
\hline 112 & 64 & 100 \\
\hline 120 & 80 & 110 \\
\hline 125 & 91 & 130 \\
\hline 130 & 110 & 140 \\
\hline 135 & 115 & 130 \\
\hline 140 & 120 & 150 \\
\hline
\end{tabular}


Palgunadi et al., 2020 BSSA Special Issue on Induced Seismicity PREPRINT

\section{LIST OF SUPPLEMENTAL FIGURES:}
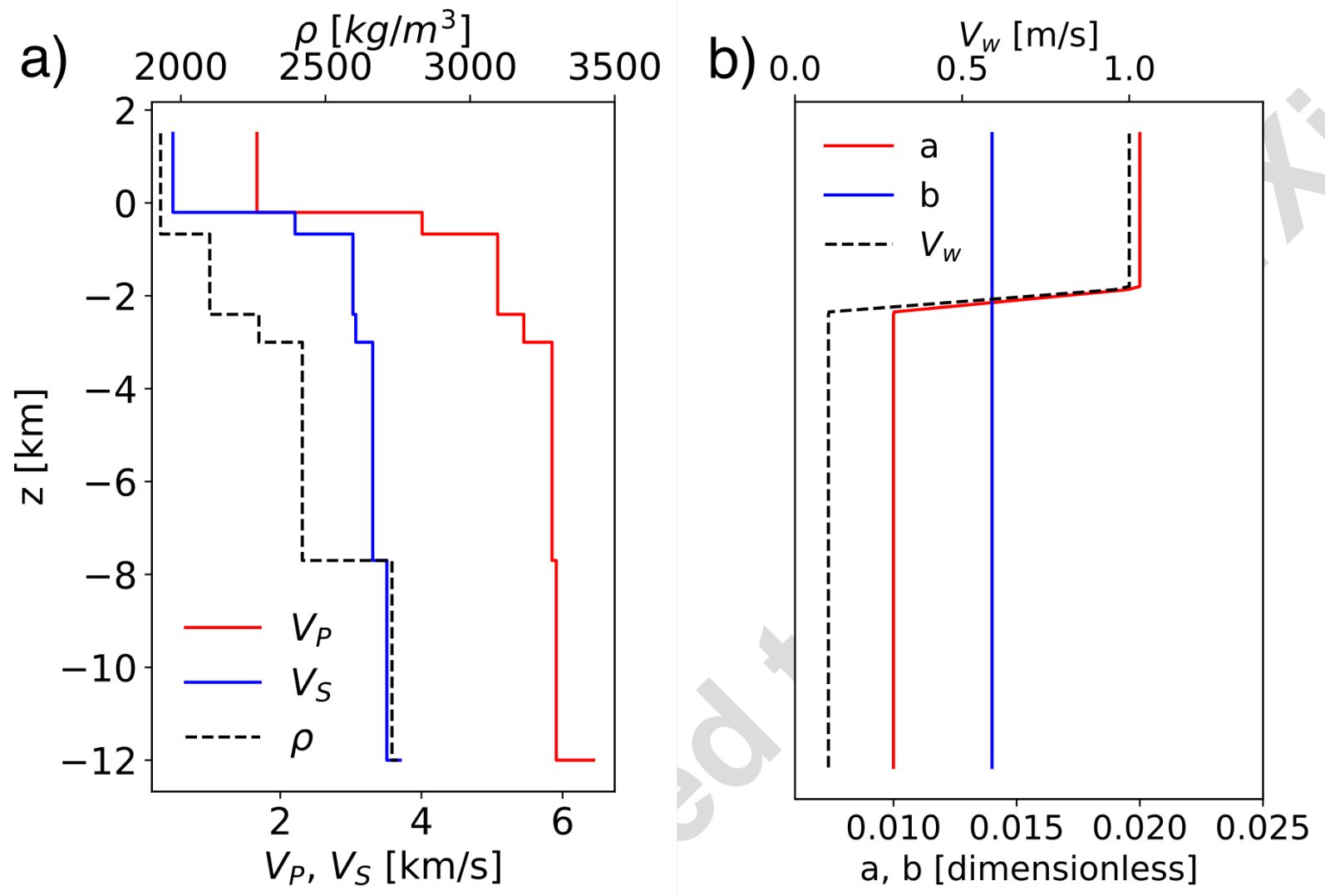

Figure S1. Vertical profiles of a) the 1-D model of seismic wave speeds by Woo et al. (2019) and by Korean Government Commission (2019). Panel b) displays the depth-dependent parameters of the velocity weakening rate-and-state friction law. 
Palgunadi et al., 2020 BSSA Special Issue on Induced Seismicity PREPRINT

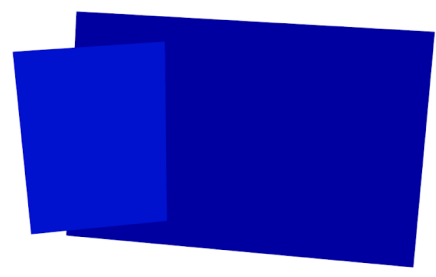

$\mathrm{S}_{\text {Hmax }}=67$

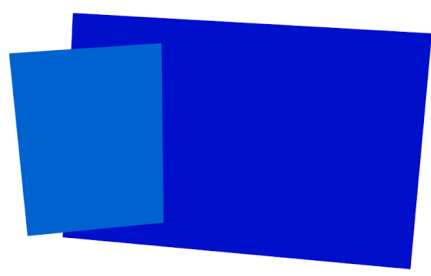

$S_{H \max }=82$

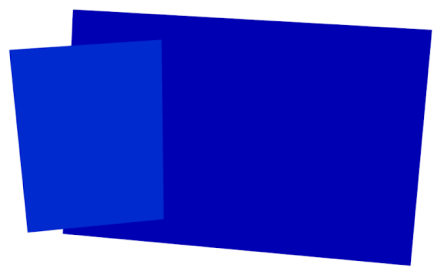

$\mathrm{S}_{\text {Hmax }}=72$

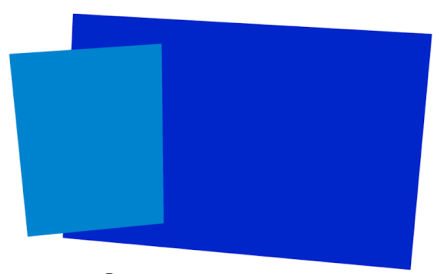

$\mathrm{S}_{\mathrm{H} \max }=87$

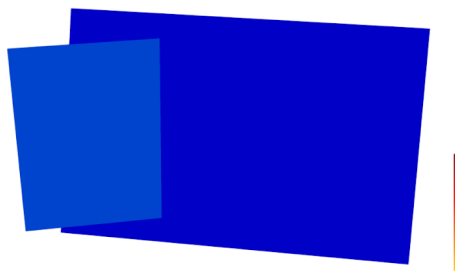

$\mathrm{S}_{\text {Hmax }}=77$

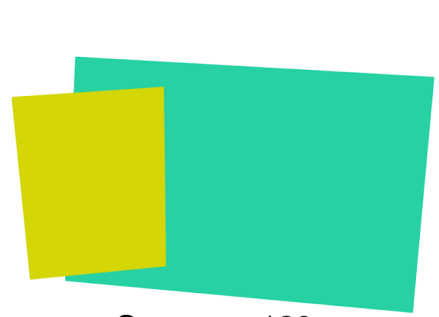

$\mathrm{S}_{\mathrm{H} \max }=120$
180.

160.

140.

120.

100. 쁜

60.

-40 .

20.

0 .

Figure S2. Rake of initial (at $t=0$ ) shear traction for exemplary orientations of maximum horizontal stress $S_{H \max }$ (see also Table S1). Thrust-faulting is favored for $S_{H \max }=120^{\circ}$. Note that $S_{\text {Hmax }}=77^{\circ}$ corresponds to the findings of Ellsworth et al. (2019). 


\section{Palgunadi et al., 2020 BSSA Special Issue on Induced Seismicity}

PREPRINT
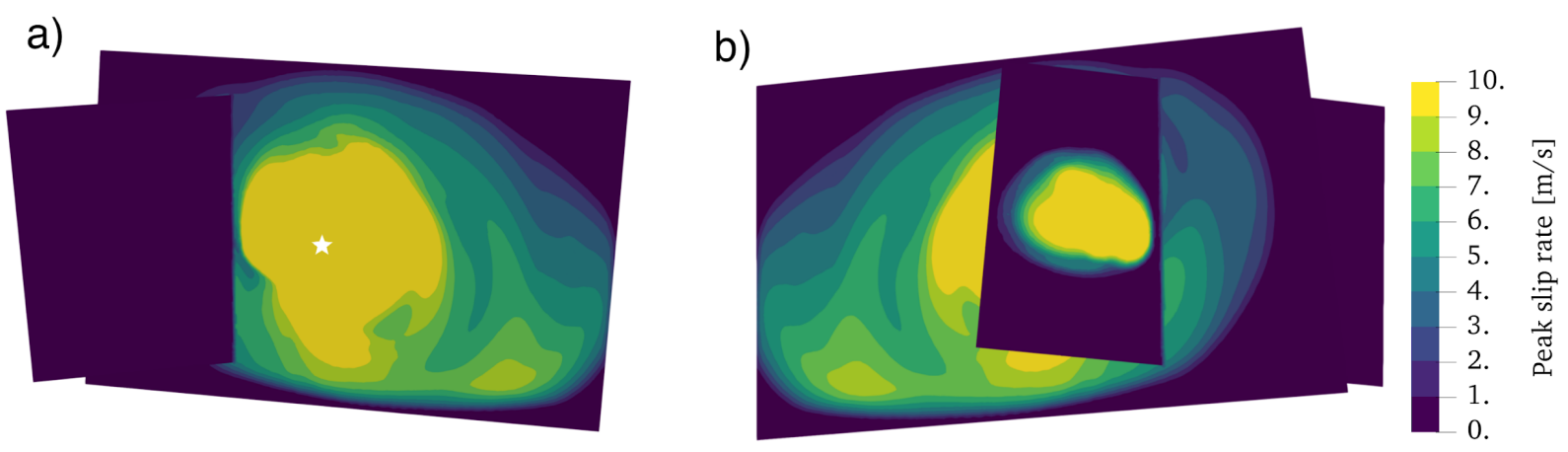

Figure S3. Peak slip rate of Model 2F. The maximum peak slip rate (yellow color, saturated at 10 $\mathrm{m} / \mathrm{s}$ ) outside the nucleation zone is $15 \mathrm{~m} / \mathrm{s}$. View from a) WNW along the averaged normal vectors of the two fault planes and b) ESE along the averaged back-normal vectors of the two fault planes. 


\section{Palgunadi et al., 2020 BSSA Special Issue on Induced Seismicity PREPRINT}

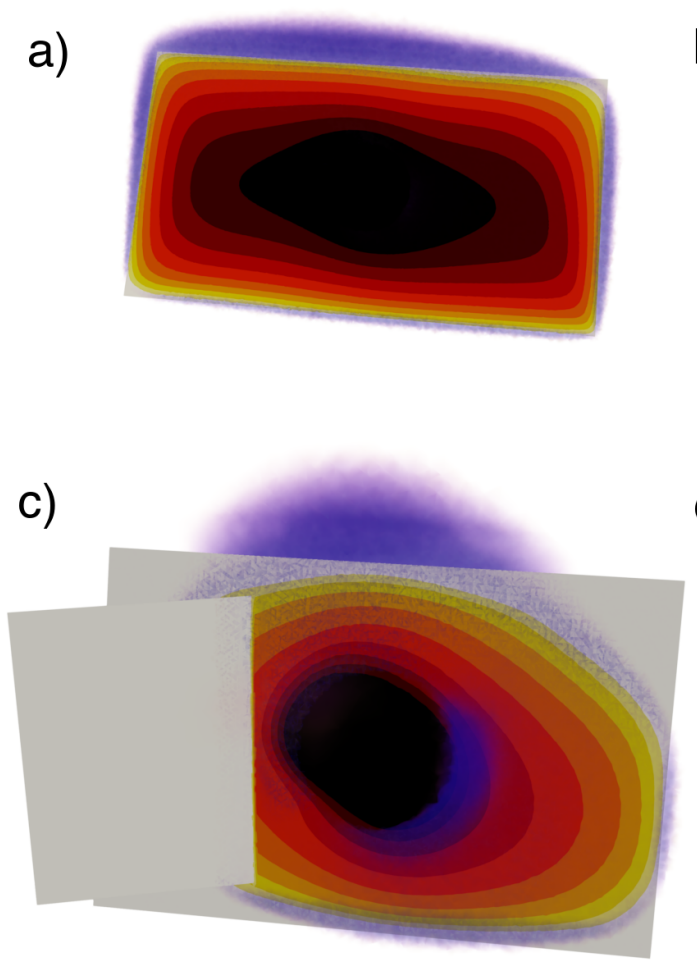

b)

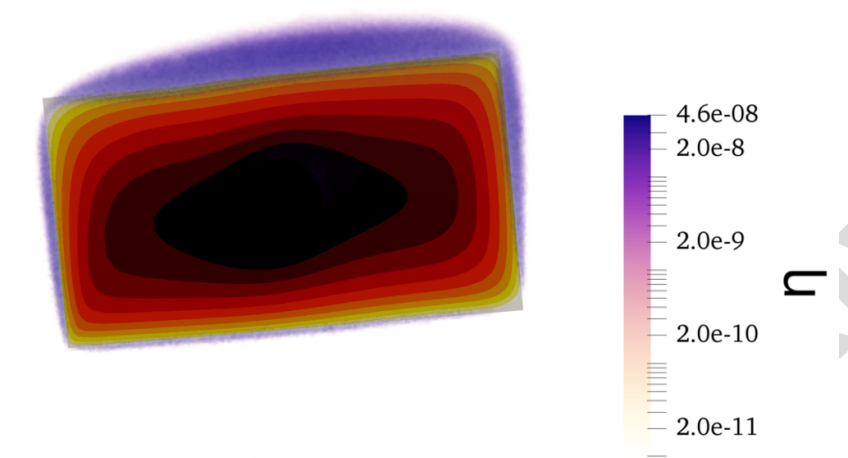

d)

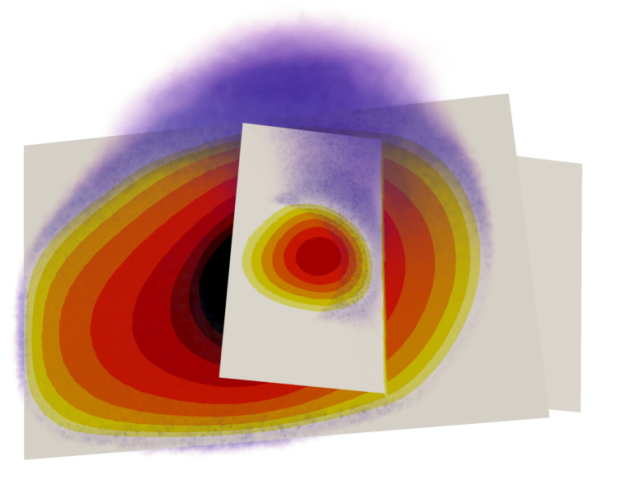

2.00

$-1.80$

$-1.60$

-1.40 当

1.00 ๘

$-0.80$

$-0.60 \stackrel{2}{2}$

$-0.40$

$-0.20$

$-0.00$

Figure S4. Asymmetric off-fault plastic deformation for Model 1F ( $a$ and b) and Model 2F (c and d). a) and c) view from WNW along the averaged normal vectors of the two fault planes b) and d) view from ESE along the averaged back-normal vectors of the two fault planes. The accumulated volumetric plastic strain is mapped into the scalar quantity $\eta$ denoted by the purple colorbar (purple color, saturated at $10^{-7}$ ). Following Wollherr et al. (2019), the characteristics of fault zone width can be qualitatively compared to the spatial distribution of the modeled co-seismic plastic deformation. We infer high co-seismic damage close to the fault intersection, and an increasing fault zone width near the surface, yet, off-fault damage not reaching the free surface. 
Palgunadi et al., 2020 BSSA Special Issue on Induced Seismicity PREPRINT
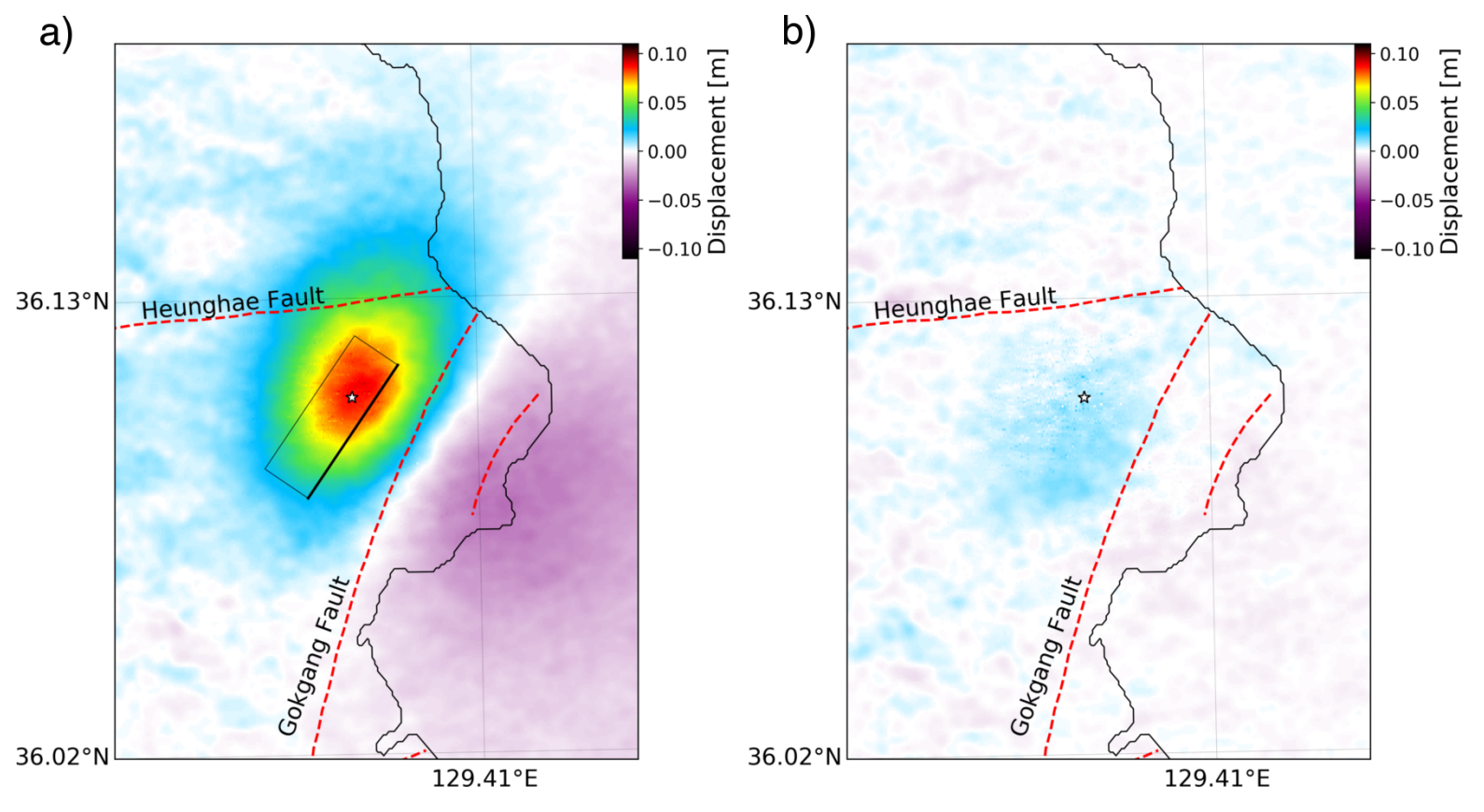

Figure S5. Modeled surface displacements of Model 2F. a) Modeled co-seismic surface displacements using only the main fault plane of Model 2F. The rectangle illustrates the fault plane. b) The difference between the modeled co-seismic displacement of Model 2F and Model 2F using only the main plane. The dashed red lines represent the traces of the interpreted faults near the EGS site. The white star represents the epicenter of the Pohang earthquake. 
Palgunadi et al., 2020 BSSA Special Issue on Induced Seismicity PREPRINT

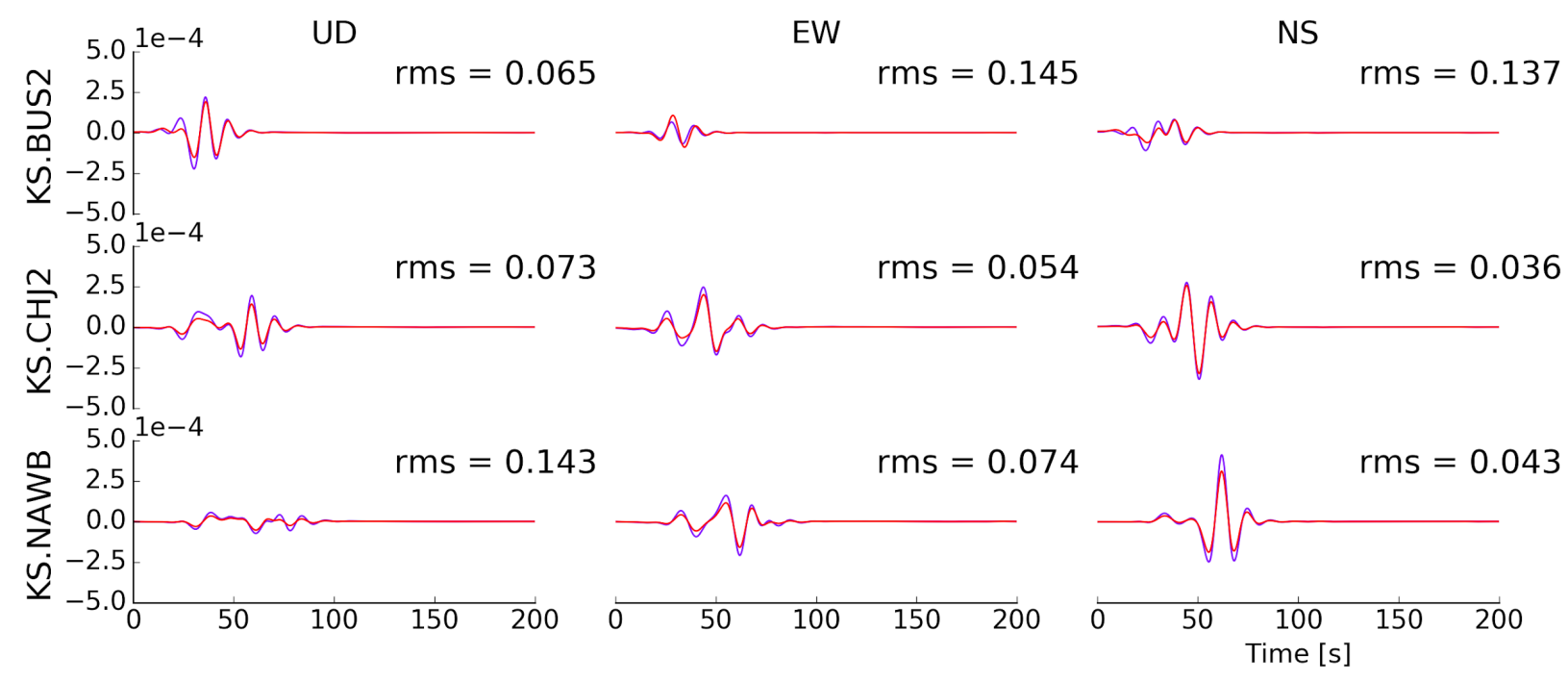

M2F - Grigoli et al., 2018

Figure S6. Waveform comparison between two synthetics generated by point source modeling of our preferred Model 2F and the moment tensor solution of Grigoli et al. (2018). $t=0 \mathrm{~s}$ denotes the origin time of the Pohang earthquake. A $0.033-0.08 \mathrm{~Hz} 4^{\text {th }}$-order Butterworth filter is applied to all traces. 
Palgunadi et al., 2020 BSSA Special Issue on Induced Seismicity PREPRINT

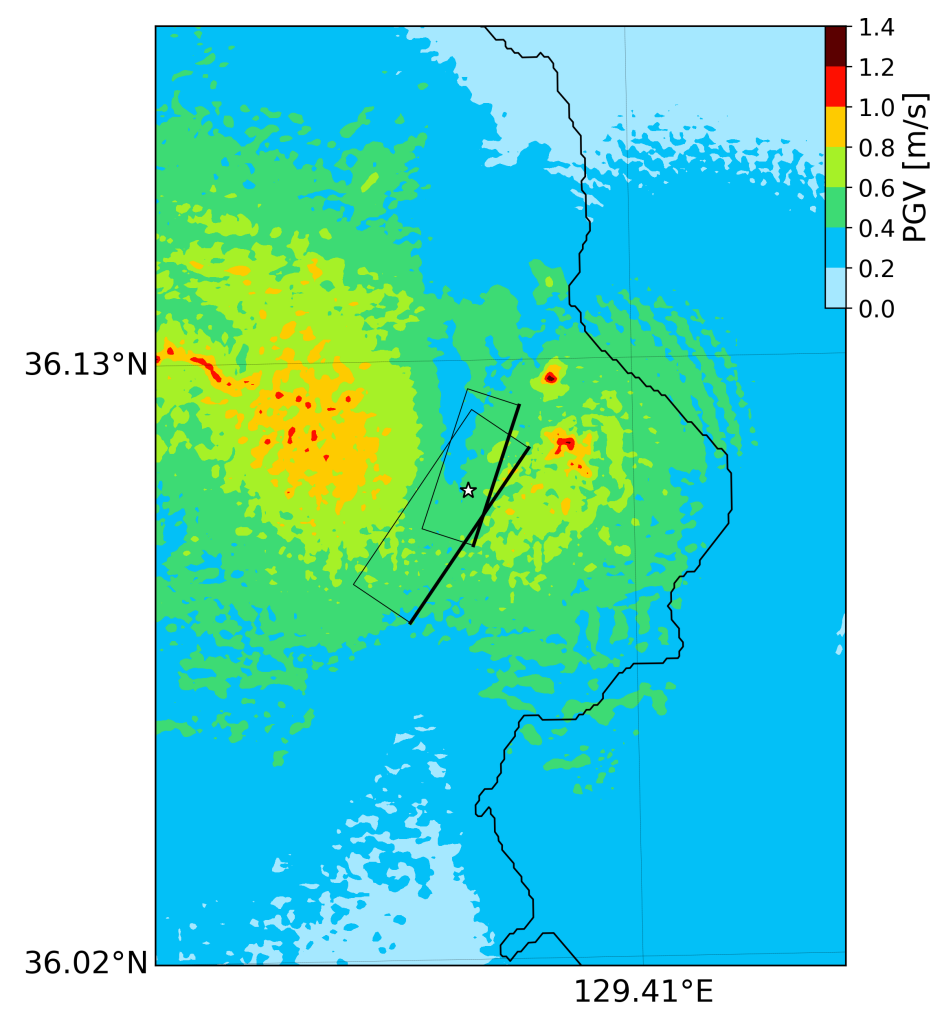

Figure S7. Peak ground velocity shake-map (in m/s, based on GMRotD50 (Boore et al., 2006)) for the preferred Model $2 \mathrm{~F}$ (color-contoured $0.2 \mathrm{~m} / \mathrm{s}$ increments). The white star denotes the epicenter of the Pohang earthquake. 


\section{Palgunadi et al., 2020 BSSA Special Issue on Induced Seismicity PREPRINT}

\section{References:}

Boore, D. M., J. Watson-Lamprey, and N. A. Abrahamson, 2006, Orientation-Independent Measures of Ground Motion, Bull. Seismol. Soc. Am., 96, no. 4A, 1502-1511, doi: $10.1785 / 0120050209$.

Ellsworth, W. L., D. Giardini, J. Townend, S. Ge, and T. Shimamoto, 2019, Triggering of the Pohang, Korea, Earthquake (Mw 5.5) by enhanced geothermal system stimulation, Seismological Society of America, 1844-1858.

Korean Government Commission, 2019, Summary Report of the Korean Government Commission on Relations between the 2017 Pohang Earthquake and EGS Project.

Wollherr, S., A.-A. Gabriel, and P. M. Mai, 2019, Landers 1992 "Reloaded”: Integrative Dynamic Earthquake Rupture Modeling, J. Geophys. Res. Solid Earth, 124, no. 7, 66666702, doi: 10.1029/2018JB016355.

Wollherr, S., A.-A. Gabriel, and P. M. Mai, 2019, Landers 1992 "Reloaded": Integrative Dynamic Earthquake Rupture Modeling, J. Geophys. Res. Solid Earth, 124, no. 7, 66666702, doi: 10.1029/2018JB016355.

Woo, J. -U., M. Kim, D. -H. Sheen, T. -S. Kang, J. Rhie, F. Grigoli, W. L. Ellsworth, and D. Giardini, 2019, An In-Depth Seismological Analysis Revealing a Causal Link Between the 2017 M w 5.5 Pohang Earthquake and EGS Project, J. Geophys. Res. Solid Earth, 2019JB018368, doi: 10.1029/2019JB018368. 
Palgunadi et al., 2020 BSSA Special Issue on Induced Seismicity PREPRINT 